\title{
ARCILLAS IDENTIFICADAS EN SUELOS DE COSTA RICA A NIVEL GENERALIZADO DURANTE EL PERÍODO 1931-2014: I. HISTORIA, METODOLOGÍA DE ANÁLISIS Y MINERALOGÍA DE ARCILLAS EN SUELOS DERIVADOS DE CENIZAS VOLCÁNICAS
}

\author{
Alfredo Alvarado ${ }^{l / *}$, Rafael Mata*, Miguel Chinchilla**

\begin{abstract}
Palabras clave: Arcilla, suelo, Andisol, vidrio volcánico, amorfos, alófanas, illita, halloysita, metahalloysita, imogolita, ferrihidrita, goethita, gibbsita, esmectita, Costa Rica, trópico. te, ferrihydrite, goethite, gibbsite, smectite, Costa Rica, tropics.
\end{abstract} \\ Keywords: Clay, soil, Andisol, volcanic glass, amorphous, allophanes, illite, halloysite, metahalloysite, imogoli-
}

Recibido: 04/06/13

\section{RESUMEN}

Se resume la información disponible sobre caracterización de arcillas en suelos de Costa Rica desde 1931 hasta el presente, descrita en 84 trabajos con 520 observaciones hasta el 2014. La discusión se basa principalmente en la mineralogía de arcilla de los horizontes superficiales del suelo, aunque se menciona la mineralogía de los horizontes B cuando ésta es diferente a la de los horizontes A de manera relevante. Después de ubicar los datos puntuales en un mapa del país, se encontró que algunas áreas cuentan con poca o ninguna información (península de Nicoya, Zona Norte y región este de la Cordillera de Talamanca). Para el área restante la información disponible se agrupó por mineralogías de "arcilla dominante", identificándose las mineralogías: (1) vidrio-amorfo-halloysítica (Andisoles y otros suelos con características ándicas); (2) esmectítica y de arcillas interestratificadas (Vertisoles y otros suelos con características vérticas); (3) óxidos-hidróxidos-oxihidróxidos-caolinita-gibbsita (Alfisoles, Ultisoles y Oxisoles); además de una serie importante de mineralogías mixtas

1 Autor para correspondencia. Correo electrónico: alfredo.alvarado@ucr.ac.cr

Centro de Investigaciones Agronómicas. Universidad de Costa Rica. San José, Costa Rica.
Aceptado: 16/10/13

\begin{abstract}
Clay minerals identified in soils of Costa Rica from 1931 to 2014: I. History, methods of analyses, and mayor clay types found in volcanic ash derived soils. Findings in a total of 84 research papers identifying clay minerals on 520 soil samples of Costa Rica are summarized. This review emphasizes on the clay minerals described in the topsoil samples, although clay minerals in the $\mathrm{B}$ horizons are also discussed when they are different to predominant mineralogy in the topsoil. Sites where soil clays information is available were geo-referenced, to observe their geographical distribution. In general most of the country possesses soil clays identified, except for the Nicoya Peninsula, the Northern Zone, and the Eastern Talamanca Range. Clay mineralogy suites ("predominant clay groups") were grouped as: (1) vitrous-amorphous-halloysitic (Andisols and other soils with andic properties; (2) smectites and interstratified clays (Vertisols and other soils with vertic properties); (3) oxideshidroxides-oxihidroxides-kaolinite-gibbsite (Alfisols, Ultisols and Oxisols); Plus a large area
\end{abstract}

\footnotetext{
** Instituto Costarricense de Electricidad. San José, Costa Rica.
} 
en suelos de poco o ningún desarrollo edáfico (Entisoles e Inceptisoles). En el texto se discute la génesis (procesos de formación) de los principales tipos de arcilla del país, cuando se contó con suficiente información para ello.

\section{INTRODUCCIÓN}

\section{Conceptos básicos}

Las arcillas son constituyentes esenciales de gran parte de los suelos y sedimentos del mundo y representan el producto final de la meteorización principalmente de silicatos. La arcilla del suelo junto con las fracciones limo y arena definen su textura y su cantidad y propiedades afectan la gran mayoría de las reacciones físicas, químicas y biológicas que ocurren en el suelo y poseen una alta superficie específica y fenómenos eléctricos superficiales que explican gran parte de los comportamientos que tiene el suelo.

En la ciencia del suelo el término arcilla tiene 2 significados: 1) toda partícula del que tenga un tamaño menor de $2 \mu \mathrm{m}$ independientemente de su composición química, a veces incluyendo la fracción limo entre 50 y $2 \mu \mathrm{m}$ y 2 ) aquel mineral que está formado por la unión de 1 o 2 láminas tetraédricas con un lámina octaédrica. Hoy en día también se consideran como arcillas los óxidos y oxi-hidróxidos, abundantes en suelos fuertemente meteorizados y los materiales "amorfos" conocidos como minerales de corto rango de cristalinidad y que pueden tener varias formas: las alofanas son esferas y las imogolitas son tubos, pero no dan señal en los difractogramas de rayos $\mathrm{X}$.

Las arcillas dominan en los minerales secundarios y representan el producto de la neoformación formándose en el suelo y el subsuelo por los procesos de meteorización de los of soils with mixed clay mineralogy, found in places with little or no development (Entisols and Inceptisols). The soil clay genesis of the main clay types in the country is discussed when enough information was available.

minerales primarios; son un reflejo de las condiciones de formación del suelo, de manera que las arcillas encontradas en suelos muy evolucionados son diferentes a aquellas encontradas en suelos con poca pedogénesis (Buol et ál. 1981, Birkeland 1984). Las arcillas del suelo están formadas por distintos arreglos de láminas de tetraedros y octaedros, las cuales forman capas. Estas capas son unidas por cationes en unos casos y en otros por una lámina de octaedros. Estas uniones de capas producen una gran diversidad de arcillas con propiedades específicas que las caracterizan. Comúnmente, las arcillas se asocian a óxidos e hidróxidos de hierro y aluminio y compuestos orgánicos de origen secundario que pueden agruparse de varias maneras (Figura 1).

El término arcilla se usa con diferentes significados: (1) desde el punto de vista mineralógico-pedológico, agrupa principalmente una serie de filosilicatos y otros compuestos de diámetro inferior a $2 \mu \mathrm{m}$ asociados a otras fracciones de óxidos e hidróxidos de Fe y Al ó materia orgánica, cuyas propiedades físico-químicas dependen de su estructura que incluye otros silicatos como el cuarzo y los feldespatos si no superan las $2 \mu \mathrm{m}$, (2) desde el punto de vista petrológico la arcilla es una roca sedimentaria de origen detrítico, (3) para un ceramista es un material natural que cuando se mezcla con agua en la cantidad adecuada se convierte en una pasta plástica y (4) desde el punto de vista económico son un grupo de minerales industriales con diferentes características mineralógicas y genéticas y con distintas aplicaciones tecnológicas. 


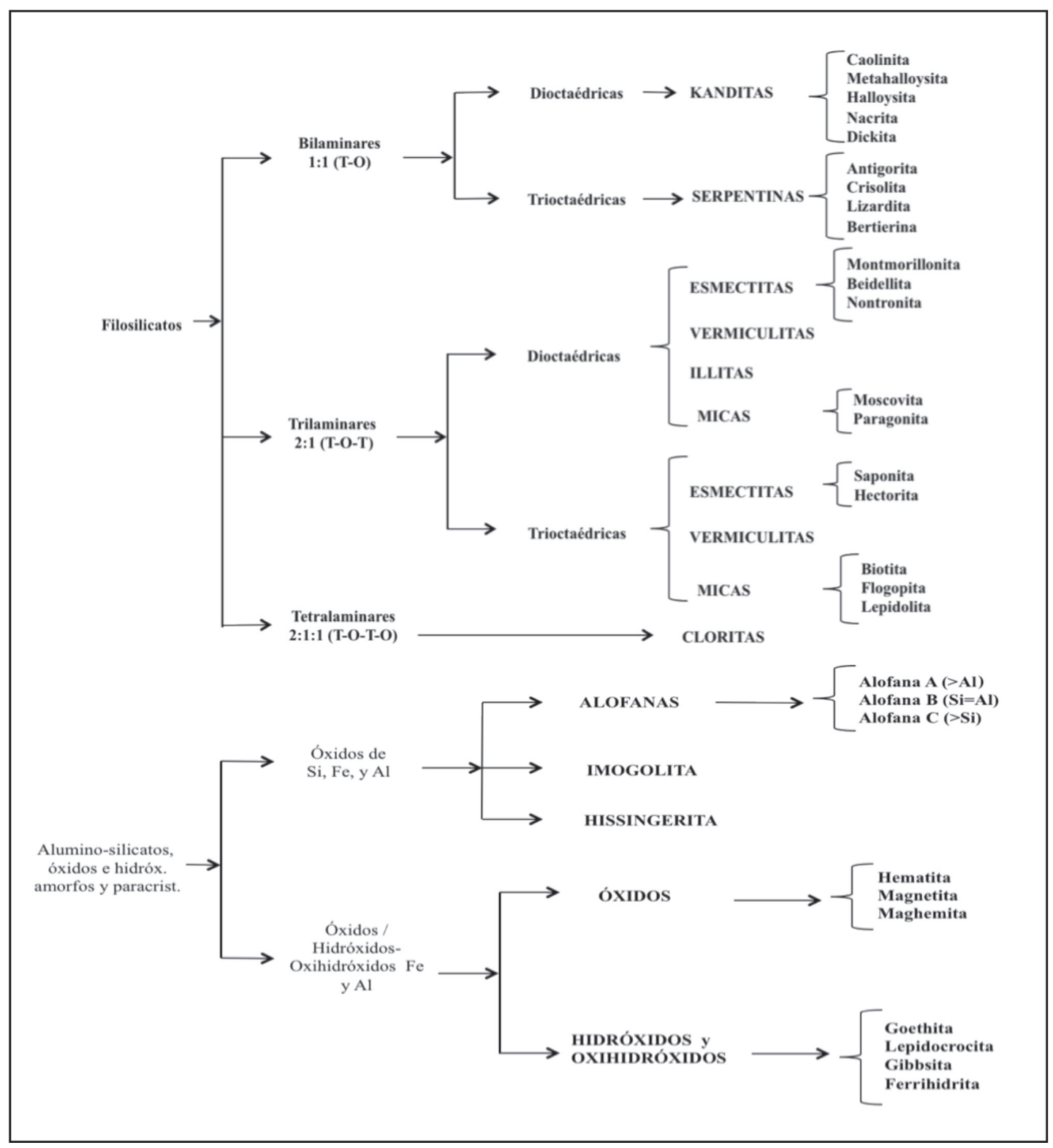

Fig. 1. Esquema de agrupamiento de los principales minerales de arcilla y óxidos e hidróxidos de hierro y aluminio. 
En estudios edafológicos, las arcillas se consideran por su importancia sobre las propiedades físico-químicas y biológicas de los suelos. Entre ellas Besoain (1985) menciona que las arcillas son "condicionadoras de la fertilidad del suelo", pues al presentar cargas negativas y algunas positivas, pueden adsorber cationes y en menor cantidad aniones y retener agua entre sus láminas. Así, al retener elementos como fósforo, nitrógeno y potasio definen la fertilidad potencial de los suelos en relación con la capacidad de intercambio catiónico (CIC) y aniónico (CIA) y la alta o baja saturación de bases. La fertilidad potencial de los suelos también se ha relacionado con la presencia de minerales primarios de fácil alteración (Malagón 1975) aunque otros autores en Costa Rica han demostrado que esta disponibilidad de nutrimentos liberados al suelo por este proceso no son suficientes para llenar las necesidades nutricionales de cultivos como el tomate a nivel de invernadero (Hardy y Bazán 1963a, 1963b). Su importancia radica en que constituyen el asiento donde ocurren la mayoría de los procesos químicos de adsorción y retención de nutrimentos y pesticidas y su posterior liberación a la solución del suelo. Las arcillas, también influyen en importantes propiedades físicas de los suelos, como la capacidad de retención de agua, velocidad de infiltración, conductividad hidráulica, adhesividad, plasticidad, contracción, expansión y los procesos de intercambio gaseoso que ocurren a nivel radicular.

Pedológicamente, los suelos que tienen horizontes Bw por acumulación de arcilla translocada del horizonte suprayacente representan los suelos de mayor grado evolutivo y normalmente se encuentran dominados por caolinita, gibbsita y óxidos e hidróxidos de hierro y aluminio, proceso que puede verse acelerado en ambientes de alteración hidrotermal o neomatolítica relacionadas con fuentes de calor de origen volcánico o por cizallamiento de falla como sucede en áreas alrededor de los volcanes Rincón de la Vieja, Miravalles, Tenorio, Irazú y Turrialba. Phillips et ál.
(2014) mencionan el caso de la colonización preferencial de anortoclasa con inclusiones de óxidos de Fe y apatita en el sistema de aguas calientes Las Pailas, volcán Rincón de la Vieja, donde se identificó que la meteorización de dichos minerales es causada por efectos químicos del agua pero también por la colonización temprana de microorganismos que se hipotetiza disuelven el $\mathrm{P}$ no disponible en la solución alrededor de los minerales primarios.

\section{Aspectos históricos de mineralogía de arcillas en suelos de Costa Rica}

Aún antes de que se escribiera la historia a partir de la conquista y colonización de Costa Rica, los grupos indígenas regionales y de culturas mesoamericanas o colombianas ya conocían, a su práctico entender, las propiedades de las diferentes arcillas con que se fabricaron los instrumentos y cerámica utilitaria y ceremonial. Igualmente utilitario desde la conquista hasta la actualidad han sido reconocidas las propiedades de las arcillas en la fabricación de tejas, ladrillos y útiles de cerámica para el uso cotidiano y ornamental, cuyos sitios y procesamiento aún se retienen en lugares como Aguacaliente de Cartago, Guatil en Guanacaste y La Uruca en San José, donde aún se hace uso de estos materiales, presentes en todas las etapas de la evolución de la humanidad y aún en sus exploraciones en el espacio.

La literatura sobre la mineralogía de las arcillas de Costa Rica es escasa y de difícil acceso. Se inicia con Anderson y Byers en 1931 y comprende un total de 84 trabajos con 510 observaciones lo que representa el 2,2\% del total de referencias sobre suelos del país hasta el año 2014, de las cuales el 77\%, 15\% y $8 \%$ corresponden a horizontes A, B y C respectivamente. Al considerar solamente la información disponible para los horizontes A (394 observaciones) se encuentra que el $45 \%$, $23 \%, 26 \%$ y $6 \%$ corresponden a arcillas amorfas, esmectitas, kanditas y óxidos e hidróxidos, respectivamente (Figura 2). 


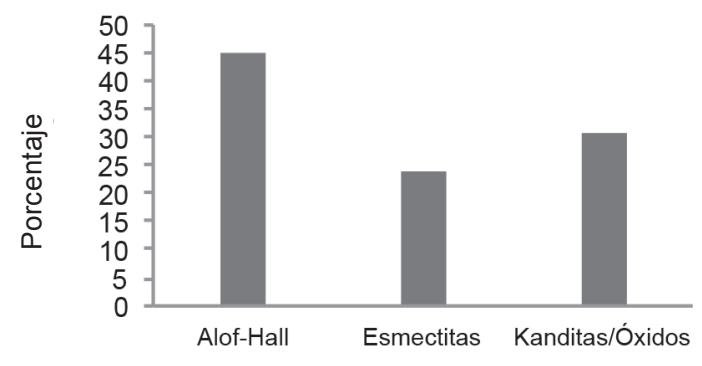

Mineralogía de arcilla dominante

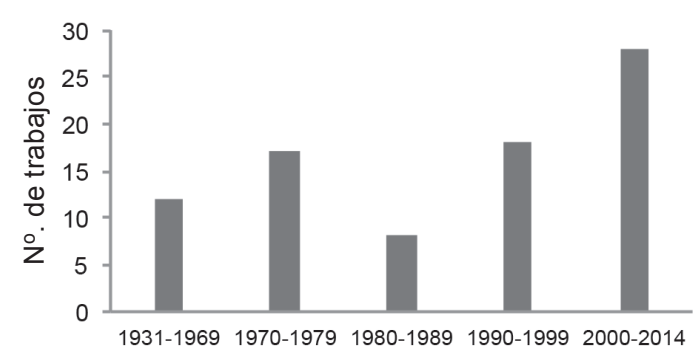

Período de análisis

Fig. 2. Trabajos sobre mineralogía de arcillas (alof-ha: amorfo-halloysítica; esmectítica; ox.caol.: oxídico-caolinítica) por década en Costa Rica durante el período 1931-2014.

Período 1931-1979: Bornemisza (1969) resume el conocimiento sobre mineralogía de arcillas en suelos de Centroamérica y Panamá (solamente 5 trabajos para Costa Rica) y reconoce la importancia que tienen: (1) las arcillas de corto rango de cristalización, asociadas con halloysita y en algunos casos con arcillas 2:1 en suelos derivados de cenizas volcánicas (Andisoles) y en otros suelos; (2) la gran variabilidad en los suelos aluviales y (3) la presencia de alófana, caolinita, halloysita y óxidos e hidróxidos de $\mathrm{Fe}$ y Al en Latosoles (actualmente clasificados como Oxisoles, Ultisoles, Alfisoles e Inceptisoles muy desarrollados). Después del trabajo de Anderson y Byers (1931) donde se caracteriza la arcilla de la serie de suelos Colombiana en la Zona Atlántica del país, el conocimiento de la mineralogía de suelos de Costa Rica se retoma a principios de la década de 1950 con fines agrícolas (Drosdorff y Pearson 1951, Fiskel e Iley 1961, López 1963, Stotzky y Martín 1963, Krezdorn et ál. 1967) o geo-agronómicos (Dóndoli 1943, 1950, Sáenz 1949, 1951, Soto y González 1956, Staff of the Cacao Program 1963, Hardy y Bazán 1963a,b) y se continúa en décadas subsecuentes a un ritmo más acelerado. Los trabajos de esta época describen de forma puntual los minerales secundarios presentes en los suelos en terrenos agrícolas planos y posteriormente en catenas a su alrededor (Besoain 1972, Alvarado y Buol 1975).
A partir de 1970 aparecen los primeros trabajos sobre génesis y mineralogía de arcillas de Costa Rica (Bornemisza e Igue 1967, Besoain 1972, González et ál. 1972, Colmet-Daage et ál. 1973, Andriesse y Muller 1973, Alvarado 1974, Tan et ál. 1975, Andriesse et ál. 1976) y otro de Holdridge et ál. (1971) en el que se relaciona por primera vez las propiedades mineralógicas de los suelos con el crecimiento y distribución de los bosques de Costa Rica.

Período 1980-2014: Durante los años de 1980 al 2014 la mineralogía de arcillas en Costa Rica se enfoca principalmente a suelos derivados de ceniza volcánica en las laderas del Valle Central, con una contribución importante por parte de la Universidad de Wageningen en suelos de la costa Caribe. A partir del año 2000 aparecen varios trabajos dedicados exclusivamente al estudio de la mineralogía de arcilla en otras partes del país (Jongmans et ál. 2000, Kautz y Ryan 2003, Meijer y Buurman 2003, Sak et ál. 2004, Fisher y Ryan 2006, Lewis et ál. 2006, Herre et ál. 2007, Scheucher et ál. 2008, Pelt et ál. 2008, Ryan y Huertas 2009, Mata et ál. 2009) o bien de proyectos hidroeléctricos y estudios ecológicos (Chinchilla 2000, Wilke et ál. 2000, Gómez y Chinchilla 2005, Kleber et ál. 2007, Winowiecki 2008, Arias et ál. 2010b, 2010c, Hardmand et ál. 2010, Salazar 2012). 
Mineralogía de arcillas en estudios geológicos: Desde la perspectiva de vista geológica, también existen trabajos importantes sobre el tema (Laguna 1983,1985, Kesel y Spicer 1985, Bertholani y Loschi-Ghittoni 1986, Rochelle et ál. 1989, Berrangé et ál. 1990, Mathers et ál. 1991, Chiesa 1991, Luijckx y Zunnenberg 1992, Sánchez 1994, Nieuwenhuyse 1996, Knoblich et ál. 1996, Cárdenes 2003b, Vega 2004, Sak et ál. 2004, Gaudin et ál. 2005, Lewis et ál. 2006, Reeves et ál. 2007, Pelt et ál. 2008, Scheucher et ál. 2008, Schembre 2009, Ryan y Huertas 2009, Charpantier et ál. 2011). Desde el punto de vista geológico-comercial destacan las arcillas que sirven como materia prima industrial, tanto por el volumen que se explota como por su valor en la cadena de producción. En este campo un $90 \%$ de la arcilla se dedica a la fabricación de materiales de construcción, cemento, ladrillos y azulejos en menor proporción y un $10 \%$ como arcillas especiales, entre ellas caolines, bentonitas, sepiolita y paligorskita, para industrias como la fabricación de papel, caucho, pinturas, absorbentes, decolorantes, arenas de moldeo, productos químicos y farmacéuticos y a la alimentación animal. En el país son importantes para uso artesanal en varios yacimientos distribuidos en el país (p.ej. en las localidades de Guaitil y Santa Ana).

En Costa Rica han llamado y recibido atención algunos materiales arcillosos originalmente descritos como caolín, luego como laterita, bauxita y posteriormente como plintita, cuyos procesos de formación se han discutido en detalle en eventos a nivel mundial (Barto-Kyriakidis 1989) y en libros de geomorfología tropical (Thomas 1994). Se define un caolín como un material que contiene una cierta proporción de minerales del grupo de las kanditas, que puede ser económicamente extraída y concentrada; se trata de una arcosa o arena caolinífera, granito o gneis caolinitizado que es necesario procesar para enriquecer el material en minerales del grupo del caolín. Las lateritas son el producto de una meteorización subaérea intensa cuyos contenidos de Fe y Al son mayores y los de Si menores a los encontrados en las rocas parentales originales pero caolinizadas; normalmente consisten predominantemente de caolinita, goethita, hematita, gibbsita y cuarzo (Schellmann 1981). Los depósitos de bauxita se originan por meteorización en el proceso de formación de suelos que culmina con un enriquecimiento de aluminio, pero no de álcalis, materiales alcalinos o sílice; por depósito bauxítico se entiende aquel que contiene no menos de 45-50\% $\mathrm{Al}_{2} \mathrm{O}_{3}$ y no más de $20 \% \mathrm{Fe}_{2} \mathrm{O}_{3}$ y $9-5 \% \mathrm{SiO}_{2}$ combinados (Valenton 1972). Se entiende por plintita (Gr. plinthos, ladrillo) una mezcla de arcilla con cuarzo y otros diluyentes, rica en hierro y pobre en humus que se presenta como concentraciones redox rojo oscuras en patrones laminares, poligonales o reticulares y cambia irreversiblemente a un pan endurecido férrico o a agregados irregulares al exponerla a humedecimientos y secados repetidos. Sáenz (1983) y Castillo (1997) mencionan que los principales recursos de aluminio de Costa Rica se encuentran en los valles de El General y Coto Brus (Figura 3), donde los depósitos de bauxita o laterita-bauxítica son el producto del proceso de laterización que afectó las terrazas fanglomeráticas del Pleistoceno (coluvios-aluvionales derivados de los flancos de la cordillera de Talamanca), correspondientes a los abanicos aluviales según Kesel y Spicer (1985). En esta región, Castillo (1997) menciona espesores de suelo de entre 2,6 y $3,0 \mathrm{~m}$ con contenidos de $31,7-34,1 \% \quad \mathrm{Al}_{2} \mathrm{O}_{3}$ y de 4,8-5,3\% $\mathrm{SiO}_{2}$, notándose que el $\mathrm{Al}$ tiende a acumularse en el subsuelo aquí y en otras regiones de Costa Rica (Harmand et ál. 2010, Wilke et ál. 2000). La presencia de bauxitas implica una meteorización muy intensa y antigua para toda la región y está en concordancia con lo encontrado por Winowiecki (2008) en Baja Talamanca. 


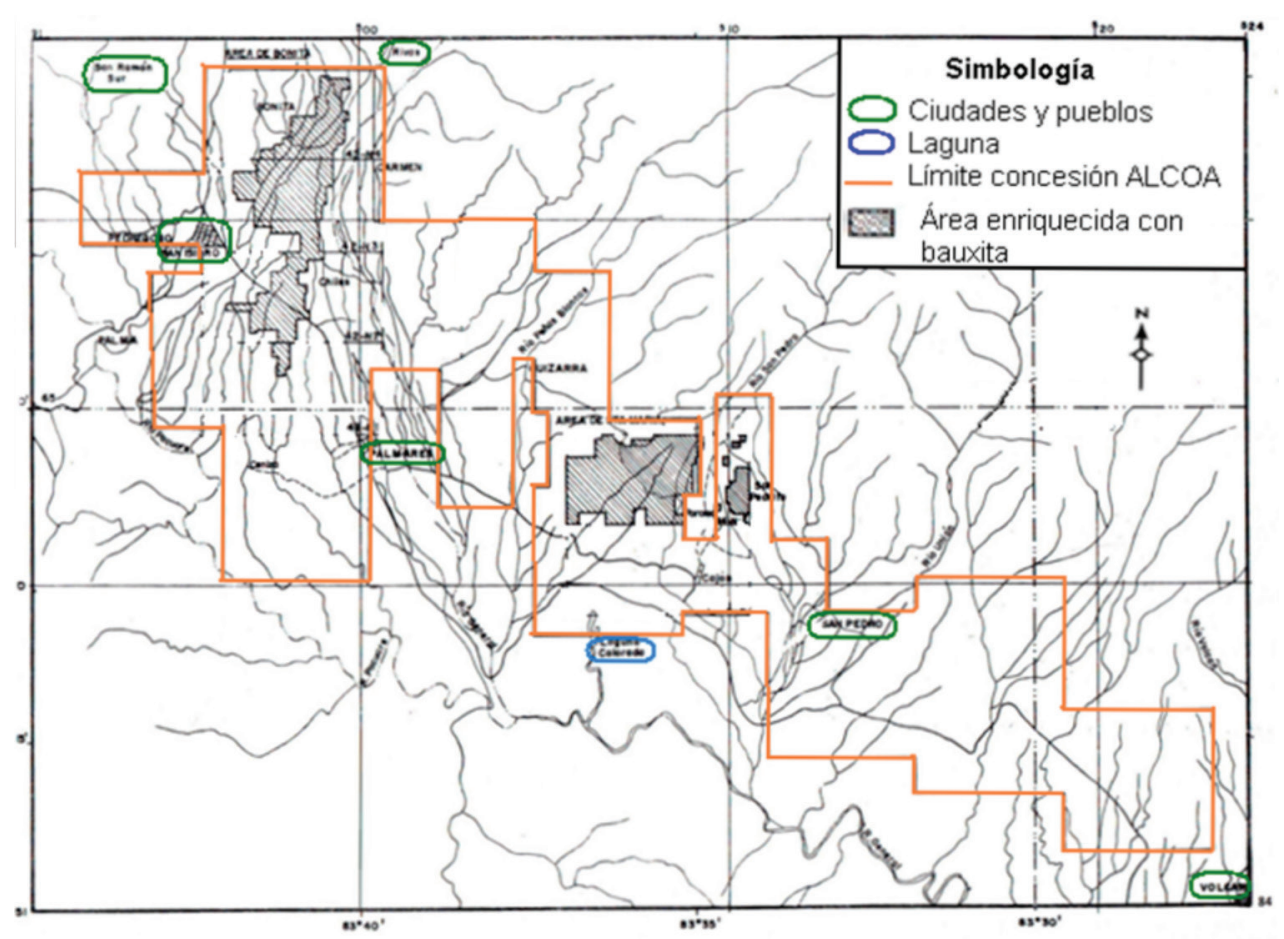

Fig. 3. Localización de los depósitos de laterita-bauxitica del valle de El General. (adaptado de Castillo 1980).

Otro tipo de arcilla de consideración geológica es la bentonita, entendiéndose por tal una roca sedimentaria compuesta esencialmente por minerales del grupo de las esmectitas, que en función de su capacidad de hinchamiento en agua se las separa como: (1) altamente hinchables o sódicas, (2) poco hinchables o cálcicas y (3) moderadamente hinchables o intermedias. Las sepiolitas y paligorskitas son materiales arcillosos de hábito fibroso con un contenido de estas arcillas superior al 50\%, con una enorme área superficial debida a su pequeño tamaño de partícula y porosidad estructural calculada alrededor de $900 \mathrm{~m}^{2} \mathrm{~g}^{-1}$, aunque la superficie accesible es muy inferior.

\section{Metodologías de análisis}

Los métodos empleados en los estudios de meteorización de suelos y en la caracterización y formación de arcillas en Costa Rica han variado con el tiempo, de manera que para la época en que se hicieron algunos de ellos no se consideraban el avance actual sobre secuencias de alteración desde el punto de vista de la termodinámica descritos en varios textos (por ej. Lindsay 1979, Sposito 1989) ni los estudios de las secuencias de alteración de las tefras, por lo que algunas secuencias de alteración y la presencia de algunos minerales arcillosos discutidas sobre Andisoles de Costa Rica hoy son cuestionadas de acuerdo con los criterios descritos por Shoji et ál. (1993).

Los primeros estudios se basaban en el análisis petrográfico (p.e. Dóndoli y Torres 1954) para identificar los minerales primarios en muestras de suelo colocadas sobre un porta-objetos y observadas en un microscopio petrográfico de luz polarizada. Así se identificaban los contenidos de óxidos de Fe, caolín y óxidos de Al, plagioclasas, piroxenos y cuarzo. En el Cuadro 1 se nota el 
Cuadro 1. Análisis mineralógico de muestras del horizonte A en suelos de la región oriental de la Meseta Central (adaptado de Dóndoli y Torres 1954).

\begin{tabular}{|c|c|c|c|c|c|}
\hline \multirow{2}{*}{$\begin{array}{l}\text { Serie de suelos } \\
\text { (consociaciones) }\end{array}$} & \multicolumn{5}{|c|}{ Valores parcial y total de los componentes minerales (\%) } \\
\hline & Óxidos de Fe & $\begin{array}{c}\text { Caolín y Óxidos } \\
\text { de Al }\end{array}$ & Plagioclasas & Piroxenos & Cuarzo \\
\hline \multicolumn{6}{|c|}{ Suelos sobre lavas andesíticas recientes } \\
\hline Cervantes $(n=10)$ & $0,3-1,4$ & $1,2-1,5$ & $0,2-4,1$ & $0,6-6,3$ & \\
\hline \multicolumn{6}{|c|}{ Suelos sobre formaciones lávicas andesíticas viejas } \\
\hline Paraíso $(\mathrm{n}=10)$ & $0,2-0,9$ & $0,2-1,2$ & $0,1-0,7$ & $0,1-1,0$ & $0,1-1,0$ \\
\hline Birrisito $(n=10)$ & $0,1-1,8$ & $0,1-2,0$ & $0,1-2,8$ & $0,1-2,6$ & \\
\hline Ventura $(n=3)$ & $0,7-1,6$ & $0,1-0,3$ & $0,1-0,2$ & $0,2-0,3$ & $0,0-0,1$ \\
\hline Colorado $(n=6)$ & $0,2-4,5$ & $0,1-0,5$ & $0,1-1,5$ & $0,0-1,2$ & $0,1-0,4$ \\
\hline \multicolumn{6}{|c|}{ Suelos sobre lavina de Cartago y correntada de barro } \\
\hline Chinchilla $(\mathrm{n}=3)$ & $0,3-1,8$ & $0,2-2,9$ & $0,2-10,9$ & $0,1-2,9$ & 0,1 \\
\hline \multicolumn{6}{|c|}{ Suelos sobre aglomerado derecho río Reventazón } \\
\hline La Hamaca $(n=4)$ & $0,6-6,1$ & $0,7-5,3$ & $0,9-12,2$ & $0,2-10,3$ & 0,3 \\
\hline \multicolumn{6}{|c|}{ Suelos sobre formaciones sedimentarias del Terciario Medio Inferior } \\
\hline Purires $(n=6)$ & $0,1-0,8$ & $0,4-2,3$ & $0,0-0,4$ & $0,2-0,6$ & $0,0-4,3$ \\
\hline Navarro $(n=3)$ & $0,6-1,5$ & $0,6-6,6$ & $0,8-9,7$ & $0,1-1,5$ & $0,1-2,6$ \\
\hline Las Vueltas $(\mathrm{n}=3)$ & $0,1-0,7$ & $0,2-4,3$ & $0,0-0,1$ & $0,0-0,4$ & $0,1-0,7$ \\
\hline \multicolumn{6}{|c|}{ Suelos sobre aluviones fluvio y depósitos fluvio-lacustres } \\
\hline Arenillas $(n=4)$ & $0,1-5,8$ & $5,0-9,3$ & $7,0-23,0$ & $2,5-17,4$ & \\
\hline El Guarco $(n=4)$ & $0,2-6,1$ & $0,4-4,1$ & $2,4-12,2$ & $2,3-10,1$ & 0,4 \\
\hline Tobosi $(n=4)$ & $0,1-3,2$ & $0,4-7,7$ & $0,0-6,7$ & $0,0-5,2$ & $0,5-9,0$ \\
\hline Ujarrás (n=2) & $1,4-1,8$ & $2,5-5,5$ & $2,1-6,9$ & $4,3-4,9$ & $0,4-0,5$ \\
\hline Reventazón (n=5) & $0,7-2,5$ & $0,9-7,5$ & $1,1-5,0$ & $1,7-3,9$ & $0,4-1,1$ \\
\hline Juray $(n=4)$ & $0,2-2,1$ & $0,3-4,2$ & $0,2-2,3$ & $1,2-3,0$ & $0,1-1,4$ \\
\hline El Instituto (n=3) & $0,5-1,4$ & $0,1-3,5$ & $0,1-5,5$ & $0,2-6,9$ & \\
\hline La Margot (n=5) & $0,2-2,0$ & $0,0-0,6$ & $0,2-1,5$ & $0,5-5,0$ & $0,1-0,2$ \\
\hline
\end{tabular}

poco grado de desarrollo edáfico de los suelos de la región oriental de la Meseta Central (Dóndoli y Torres 1954) ya que los contenidos de plagioclasas (0 y 23\%) y piroxenos (0 y 17,4\%) son mucho mayores que los óxidos de $\mathrm{Fe}(0,1$ y $6,1 \%)$, el caolín y los óxidos de $\mathrm{Al}(0,2$ y 9,3\%) resultado de su meteorización.
Posteriormente, se incorporó el análisis químico total, con el fin de cuantificar la acumulación o la pérdida de elementos en el suelo, tal como hizo Chirinos (1957) quien al describir la Serie Sáenz en la Estación Experimental Agrícola de la Universidad de Costa Rica indicó que los minerales primarios disminuían con la 
profundidad del perfil, mientras que los minerales caolinizados aumentaban; sin embargo, los contenidos totales de Al, Fe y Mn no seguían el mismo patrón por lo que se asumió que salen del sistema junto con los elementos $\mathrm{Mg}, \mathrm{Ca}, \mathrm{Na}$ y $\mathrm{K}$, pero en menor cantidad (Cuadro 2).

A partir de 1970, los autores emplearon diferentes metodologías de análisis entre las cuales resaltan los métodos de reactividad como el valor delta de la CIC, la reacción al fluoruro de sodio, la retención de fosfatos (Cuadro 3), los métodos de disolución selectiva como ebullición en $\mathrm{NaOH}$, extracción con pirofosfato de sodio, oxalato de amonio y ditionito/citrato (Cuadro 4) y los métodos físicos convencionales (difracción de rayos $\mathrm{X}$ y de infrarrojo, análisis

Cuadro 2. Análisis petrográfico y composición química total de la Serie Sáenz en la Estación Experimental Agrícola de la Universidad de Costa Rica (adaptado de Chirinos 1957).

\begin{tabular}{|c|c|c|c|}
\hline \multirow{2}{*}{ Minerales/Elementos } & \multicolumn{3}{|c|}{ Horizonte (prof. cm) } \\
\hline & A $(0-40)$ & B $(40-100)$ & $C(100-200)$ \\
\hline \multicolumn{4}{|c|}{ Contenido mineralógico (\%) } \\
\hline Feldespato & 15,7 & 8,4 & 3,0 \\
\hline Piroxeno y Anfíbol & 7,8 & 5,0 & 2,7 \\
\hline Óxidos & 5,9 & 5,0 & 5,4 \\
\hline Piezas caolinizadas & 70,5 & 81,4 & 89,0 \\
\hline \multicolumn{4}{|l|}{ Elementos totales (\%) } \\
\hline $\mathrm{Al}$ & 19,3 & 18,9 & 14,0 \\
\hline $\mathrm{Fe}$ & 10,8 & 10,5 & 8,6 \\
\hline $\mathrm{Mn}$ & 0,2 & 0,1 & 0,1 \\
\hline $\mathrm{Mg}$ & 0,9 & 0,5 & 0,7 \\
\hline $\mathrm{Ca}$ & 1,0 & 0,5 & 0,6 \\
\hline $\mathrm{Na}$ & 0,5 & 0,1 & 0,1 \\
\hline $\mathrm{K}$ & 0,4 & 0,1 & 0,1 \\
\hline
\end{tabular}

Cuadro 3. Valores de retención de P, pH en NaF y Al activo en subórdenes de Andisoles de Costa Rica (adaptado de Canessa et ál. 1986).

\begin{tabular}{cccc}
\hline Gran Grupo de suelo & P retenido $\%$ & pH NaF & Al activo $\%$ \\
\hline Udivitrands & $66-76$ & $8,9-9,9$ & $0,28-1,54$ \\
Hapludands & $73-91$ & $8,9-11,2$ & $0,69-3,62$ \\
Hydrudands & $89-95$ & $10,7-11,6$ & $1,50-5,42$ \\
\hline
\end{tabular}

Cuadro 4. Valores de los contenidos de Fe y Al extraídos con oxalato de amonio, el P retenido y capacidad de intercambio catiónico efectiva (CICE) (estimada mediante Olsen- $\mathrm{KCl}$ modificado), criterios empleados para identificar materiales amorfos (adaptado de Chinchilla et ál. 2011b).

\begin{tabular}{|c|c|c|c|c|c|}
\hline \multirow{2}{*}{ Clase de suelo } & \multicolumn{2}{|c|}{$\mathrm{Al}_{\mathrm{o}}+1 / 2 \mathrm{Fe}_{\mathrm{o}}(\%)$} & \multicolumn{2}{|c|}{$\mathrm{P}$ retenido $(\%)$} & \multirow{2}{*}{$\begin{array}{c}\text { CICE cmol(+). } 1^{-1} \\
\text { Val. reales }\end{array}$} \\
\hline & Val. reales & Val. críticos & Val. reales & Val. críticos & \\
\hline Andisol & 4,0 & $>2$ & 93 & $>90$ & 3,18 \\
\hline Ultisol ándico & 2,0 & $1-2$ & 84 & $75-90$ & 4,09 \\
\hline Ultisol típico & 0,3 & $<1$ & 71 & $<70$ & 1,04 \\
\hline
\end{tabular}


térmico diferencial y microscopía electrónica, entre otros).

\section{DISTRIBUCIÓN ESPACIAL DE LOS TIPOS DE ARCILLA EN EL HORIZONTE SUPERIOR DEL SUELO EN COSTA RICA}

Las áreas con mayor densidad de observaciones de mineralogía de arcillas en Costa Rica (Figura 4) coinciden con aquellas en las cuales dominan los cultivos de exportación como banano y cacao en los suelos de origen aluvial del Atlántico y banano, cacao y palma aceitera en los suelos de origen aluvial del
Pacífico, así como en las cordilleras volcánicas donde varias instituciones internacionales han tenido proyectos de investigación. En la Figura 4 se muestra la distribución en el país de los "tipos de arcilla dominantes" (alófanas, esmectitas, kanditas y oxi-hidróxidos), mencionadas por los investigadores que las identifican como más abundantes en el horizonte superficial y en algunos casos en todo el perfil del suelo. La distribución de los puntos deja ver que existen algunas regiones en las cuales el número de estudios sobre mineralogía de arcillas en los suelos es nula o casi nula, identificadas como tales la península de Nicoya, la Zona Norte y la región este de la cordillera de Talamanca.

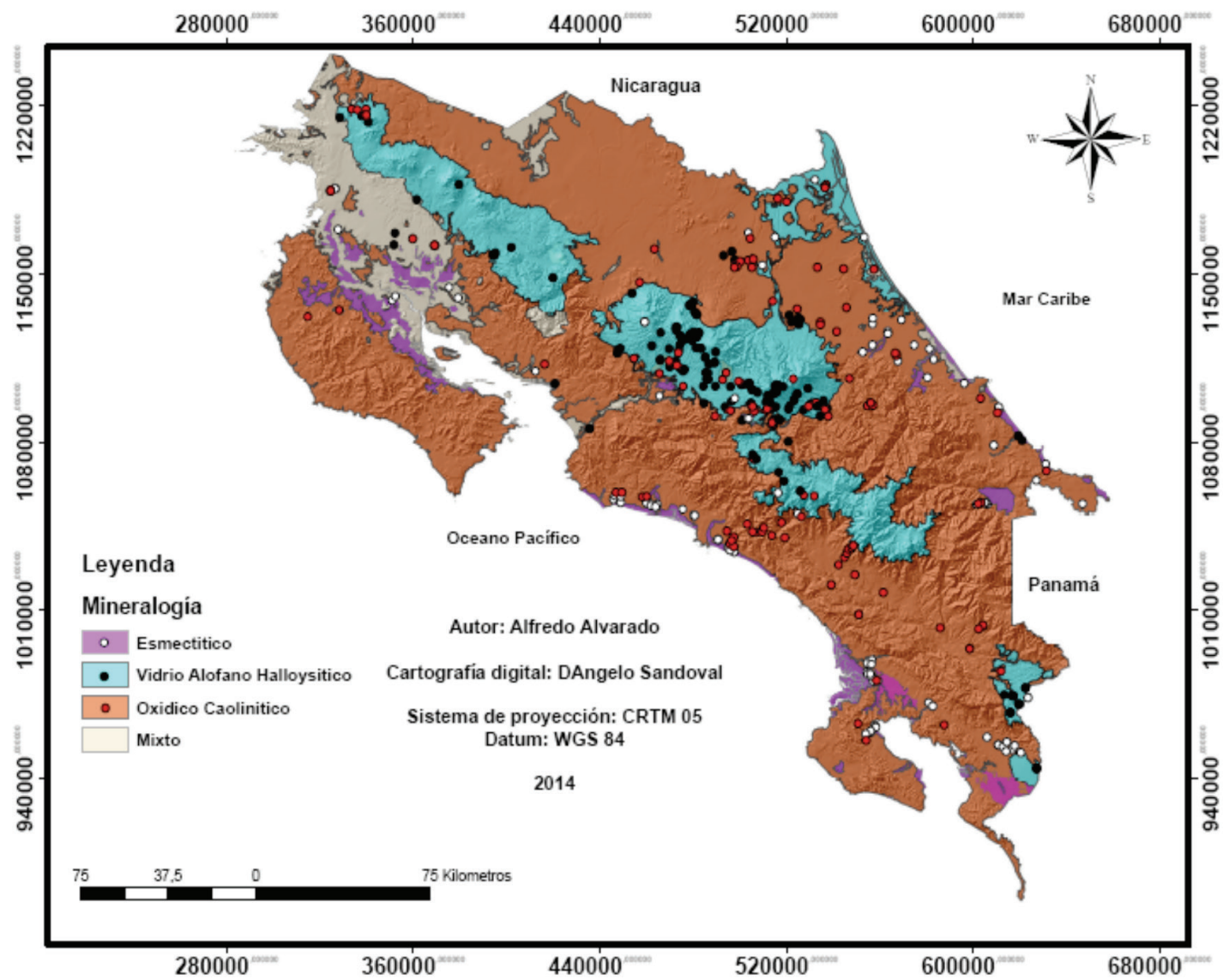

Fig. 4. Distribución espacial de los tipos de arcilla dominantes en el horizonte superior del suelo (puntos) por unidades edáficas (colores) de Costa Rica hasta 2014. 
Al trasponer los puntos de arcillas dominantes caracterizadas en el suelo superficial (horizonte A) al mapa de órdenes de suelos de Costa Rica se obtiene una extrapolación de áreas con posible dominio de las arcillas identificadas (Figura 4). Para este fin se consideran los sistemas: (1) vítrico-alófanico-halloysítico para todos los Andisoles; (2) esmectítico-interestratificados para todos los Vertisoles y los Inceptisoles aluviales de costa y (3) oxídico-caoliníticos los órdenes Alfisoles y Ultisoles, ya que hasta el presente los Oxisoles no han sido cartografiados. En términos de superficie total el sistema oxídico-caolinítico sería el más relevante del país, aunque quedarían extensas áreas en las que faltaría definir su mineralogía dominante.

\section{PRINCIPALES TIPOS DE ARCILLAS DE COSTA RICA}

De manera similar a lo encontrado por Bornemisza (1969) en suelos de Centroamérica, los tipos de arcilla encontrados en los suelos del país pueden agruparse como de mineralogía dominante en los siguientes tipos: (1) "vidrioarcillas de corto rango de cristalización-halloysítica" en las áreas de vulcanismo activo reciente, (2) "esmectita-interestratificada" en los ambientes aluviales principalmente cercanos a las costas y (3) "óxidos-hidróxidos-caolinita-gibbsita" normalmente en suelos muy desarrollados sobre las laderas de las cordilleras. Además de los sistemas de mineralogía de suelos antes mencionados se presentan situaciones particulares en las cuales es común que por falta de desarrollo edáfico ningún tipo de arcilla es dominante. La realidad es que bajo las condiciones de desbalance isostático (temblores y terremotos) y la posibilidad de deslizamientos, inundaciones periódicas, lluvias torrenciales por períodos cortos y por la fuerte erosión hídrica y eólica en algunos lugares, la tasa de formación de suelo es casi igual o menor a su tasa de pérdida, por lo que la fracción de arcilla que se puede medir y caracterizar en los suelos así formados es muy variable. Ello da lugar a lo que se conoce como mineralogías mixtas, principalmente presentes en Entisoles e Inceptisoles en las que las arcillas retrabajadas son dominantes. Así, los principales grupos mineralógicos del país a discutir seguidamente de acuerdo con su grado de desarrollo edáfico son:

1. Andisoles y otros suelos con propiedades ándicas (mineralogía vidrio-arcillas corto rango de cristalización-halloysítica).

2. Vertisoles y otros suelos con propiedades vérticas (mineralogía esmectítica y de arcillas interestratificadas).

3. Alfisoles, Ultisoles y Oxisoles (mineralogía de óxidos-hidróxidos-caolinita-gibbsita).

\section{ANDISOLES Y SUELOS CON CARACTERÍSTICAS ÁNDICAS (VIDRIO VOLCÁNICO-ALÓFANAS-HALLOYSITAS)}

\section{Cenizas volcánicas y vulcanismo en Costa Rica}

Barquero y Sáenz (1987) documentaron la existencia de 112 aparatos volcánicos en el territorio nacional a elevaciones que oscilan entre $100 \mathrm{y}$ $3549 \mathrm{msnm}$, algunos de los cuales eyectan piroclastos con cierta recurrencia y ocasionalmente nubes ardientes, bloques, lavas, bombas y gases ácidos (Figura 5). Por su lado, Alvarado (2000) reconoció la ocurrencia de por lo menos 290 focos o aparatos volcánicos en el país, de los cuales solamente 20 sobresalen por su altura y actividad reciente, una parte con fuerte actividad durante el Terciario y el resto de actividad durante el Cuaternario. La mayoría de la eyecciones de piroclastos caen en la vertiente pacífica del país, como documentó Martini (1969) para Centroamérica y más recientemente otros autores para Costa Rica y Panamá en los volcanes Rincón de la Vieja (Campos 1997, Soto et ál. 2003), Miravalles (Vega et ál. 2005), Irazú (Clark et ál. 2006), Turrialba (Reagan et ál. 2006) y Barú (Sherrod et ál. 2008).

Según Shoji (1986) el término ceniza volcánica se refiriere colectivamente a eyecciones volcánicas o tefra, incluyendo deposiciones de piroclastos y de materiales de flujo (ceniza volcánica, 


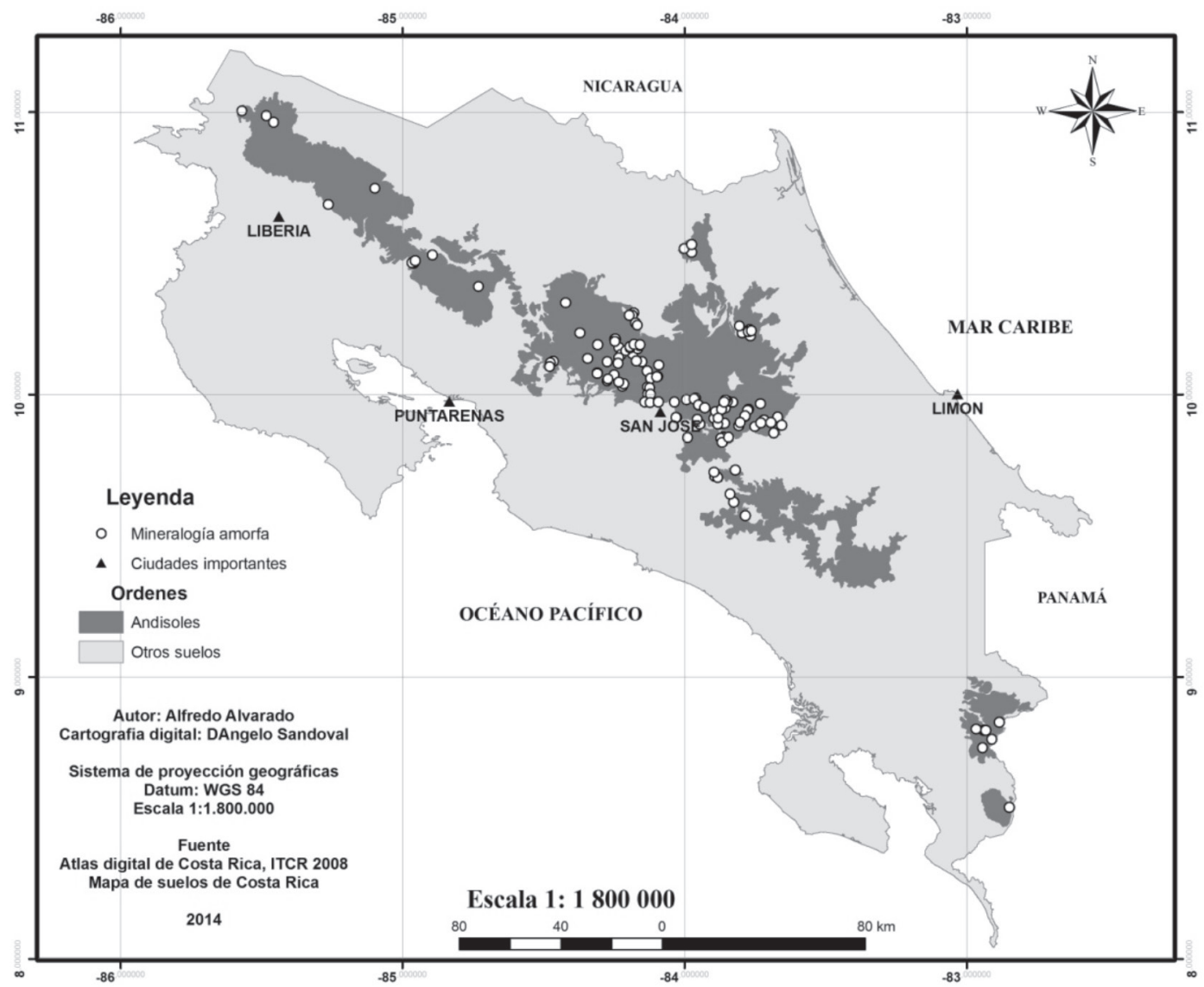

Fig. 5. Distribución de Andisoles y mineralogía de arcillas amorfas en Costa Rica (tomado de Alvarado 2000 y Mata et ál. 2012).

pómez y escoria). Los materiales mencionados se encuentran dominados por vidrio volcánico fino, poroso y permeable y por ende de poca resistencia a la meteorización química; su rápida meteorización conlleva a la formación de arcillas de corto rango de cristalización.

La elevada actividad volcánica de Costa Rica permite la formación de Andisoles asociados con Entisoles (p.ej. lavas y cenizas muy recientes) que se estima representan un área superior a las 700000 ha, equivalentes al 14\% del área total del país (Mata et ál. 2012). Además, otros suelos de mayor grado de desarrollo que los Andisoles, entre ellos Alfisoles y Ultisoles cubiertos por depósitos de cenizas volcánicas recientes en forma eólica y algunos Inceptisoles también se han visto afectados por depósitos coluviales, coluvio-aluviales que contienen ceniza retrabajada, producto de la erosión y deslizamientos en áreas aledañas a los volcanes, como ocurre en la Zona Atlántica. Alvarado et ál. (2010) mencionan la ocurrencia de áreas de Andisoles en (1) Guanacaste, (2) el Valle Central, (3) la Zona Sur y (4) pequeñas áreas en Talamanca y la Zona Atlántica y es en este tipo de suelos en los que tiende a dominar la mineralogía "vidrio-minerales de corto rango de cristalizaciónhalloysítica", condicionada principalmente por la variación climática inducida por diferencias en 
elevación sobre el terreno y en menor grado por la mineralogía del material parental, ya que en su mayoría los depósitos de ceniza del país son de composición andesítico-riolítico (Alvarado 2000).

En un inicio, para estudiar arcillas en Andisoles se tuvo que resolver el problema de su dispersión, fuera por su secado irreversible (Forsythe 1972) o por su poca dispersión en medios ácidos o básicos (Colmet-Daage et ál. 1973). Otros estudios sobre mineralización de las cenizas y rocas volcánicas y la formación de arcillas de estos materiales se iniciaron a partir de la década de los sesenta (López 1963, Bornemisza e Igue 1967, Bornemisza 1969, Bornemisza y Pineda 1969, Harris 1971a,b, Besoain 1972, González et ál. 1972, Forsythe 1972, González 1972, Andriesse y Muller 1973, Colmet-Daage et ál. 1973, Alvarado 1974, 1982, Tan et ál. 1975, López 1978, Landaeta et ál. 1978, Gómez et ál. 1981, Laguna 1983, 1985, Bertolani y LoschiGhittoni 1986, Grieve et ál. 1990, Herrera 1990, van Dooremolen et ál. 1990, Knoblich et ál. 1996, Nieuwenhuyse y van Breemen 1997, Buurman et ál. 1997, Soto 1998, Jongmans et ál. 2000, Kautz y Ryan 2003, Meijer y Buurman 2003, Herre et ál. 2007, Kleber et ál. 2007, Arias et ál. 2010b,c, USDA/SCS 2012).

Los primeros enfoques utilizados para caracterizar los cambios ocasionados por la meteorización en suelos del país incluyen el análisis petrográfico y el análisis químico total, este último empleado para estimar la acumulación de óxidos e hidróxidos de $\mathrm{Fe}$ y $\mathrm{Al}$ en relación con la pérdida de Si, calculado con los Índices de Niggli también llamados relaciones sílice sesquióxidos (Sáenz 1969). Como se menciona en la sección de métodos de análisis, hoy en día el estudio de las arcillas en Andisoles se hace uso de diferentes métodos que se utilizan específicamente para su identificación taxonómica, como el valor delta de la CIC, la reacción al fluoruro de sodio, la retención de fosfatos, los métodos de disolución selectiva como ebullición en $\mathrm{NaOH}$, extracción con pirofosfato de sodio, oxalato de amonio y ditionito/citrato y los métodos físicos convencionales. Algunos ejemplos se incluyen en los Cuadros 3 y 4 , donde se puede observar la variación de parámetros como el $\mathrm{P}$ retenido, el $\mathrm{pH}$ en $\mathrm{NaF}$ (métodos de reacción) y el $\mathrm{Al}$ activo y $\mathrm{Al}$ y $\mathrm{Fe}$ extraídos con ditionito-citrato (métodos de disolución) en Andisoles (Alvarado 1984, Canessa et ál. 1986, Chinchilla et ál. 2011a, Andriesse et ál. 1976). La acumulación de las formas de Al y $\mathrm{Fe}$ activas determina la fuerte influencia de las propiedades físicas, químicas y de productividad de los Andisoles, suelos en los que se combinan con la alófana, la imogolita, forma complejos $\mathrm{Al} /$ Fe-humus y ferrihidrita.

En la Figura 6 puede verse una representación generalizada de los procesos de formación de arcillas a partir de feldespatos y de disolución y re-cristalización a partir de vidrios volcánicos; las secuencias conducen a la posible formación de illita, vermiculita, clorita y montmorillonita a partir de los feldespatos, mientras que a partir del vidrio volcánico tiende a formarse alófana, metahalloysita, halloysita y finalmente caolinita y óxidos e hidróxidos de Fe y Al.

En la Figura 7 puede observarse otros mecanismos de formación y transformación de arcillas y complejos órgano-minerales en suelos derivados de cenizas volcánicas de regiones de clima údico templado según Wada (1989). Al presente no existe un consenso acerca de la formación de arcillas tipos 2:1 y 2:1:1 en suelos derivados de cenizas volcánicas a pesar de las variadas hipótesis de formación estudiados en varias partes del mundo, incluyendo Costa Rica. 


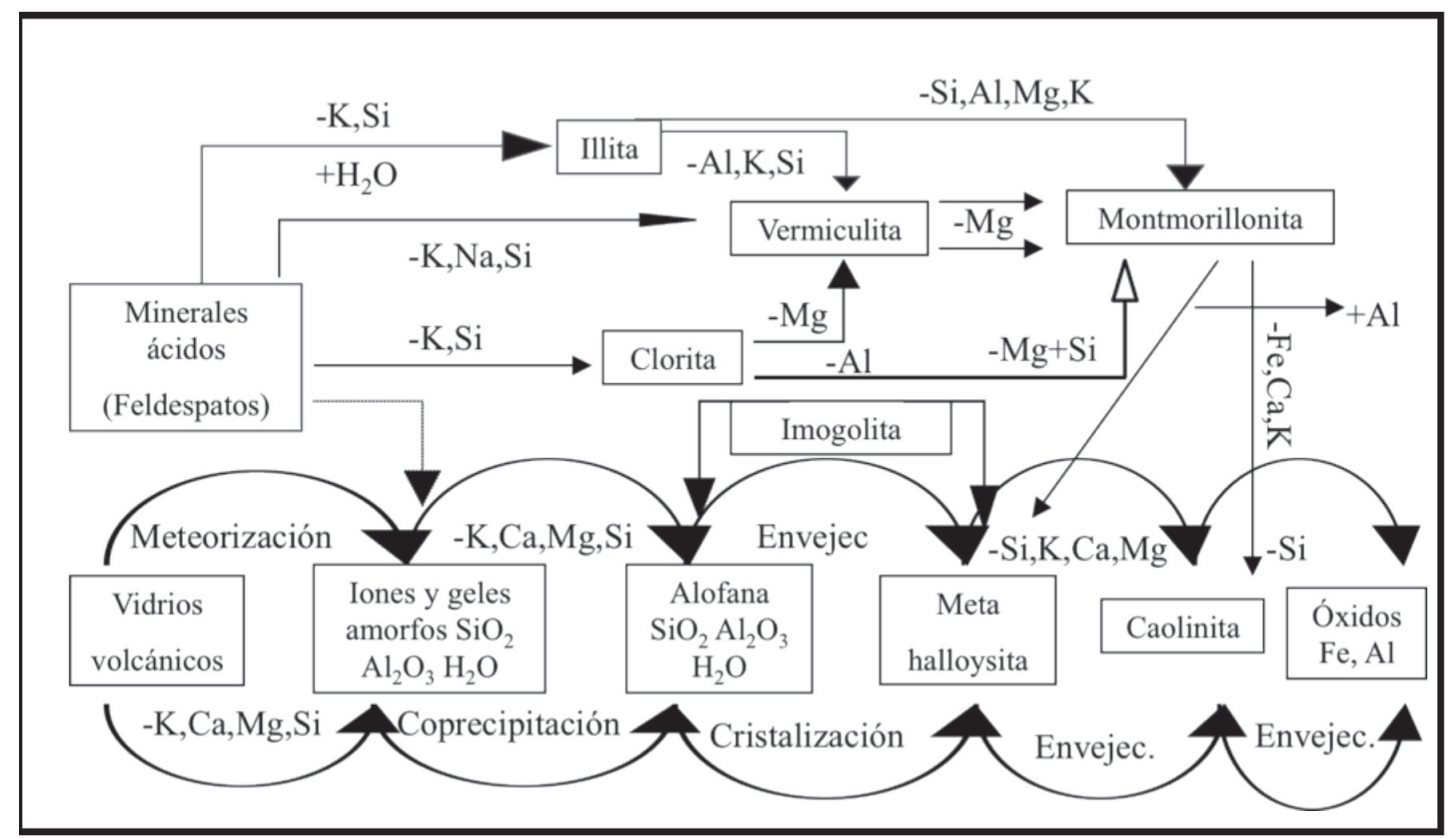

Fig. 6. Algunos mecanismos de formación de arcillas a partir de feldespatos y vidrio volcánico en Andisoles (tomado de Besoain 1985).

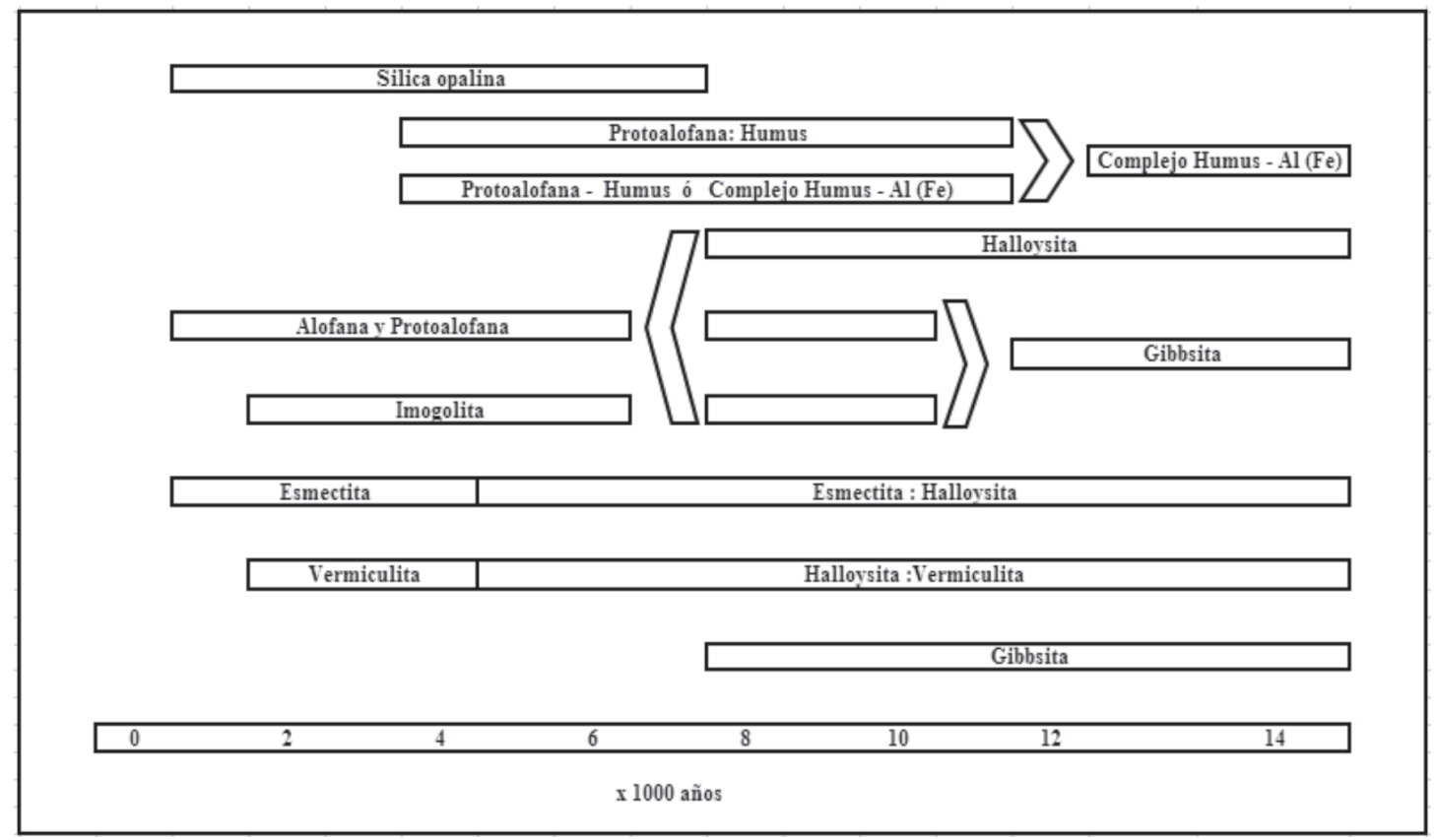

Fig. 7. Formación y transformación de arcillas y complejos órgano-minerales en suelos derivados de cenizas volcánicas de regiones de clima údico templado. Las barras horizontales muestran el tiempo aproximado que se requiere para formar los respectivos constituyentes (tomado de Wada 1989). 


\section{Definición, características y procesos de formación del vidrio volcánico}

Se considera como vidrio volcánico al grupo de minerales vítreos y vítreos-recubiertos ricos en sílice; estos materiales son un componente dominante en tefras relativamente poco meteorizadas cuya transformación puede producir minerales de baja cristalinidad tales como alófana, imogolita y ferrihídrita. Su contenido se considera como el porcentaje de vidrio (por conteo de granos), granos minerales revestidos de vidrio, agregados vítreos y materiales vidriosos en la fracción de 0,02 a 2,0 $\mu \mathrm{m}$ tal como se reportaba en estudios petrográficos del suelo (Murata et ál. 1966, Chaves 1969). Se considera como vidrio volcánico un material translúcido, ópticamente isotrópico o pómez de cualquier color que incluye vidrio, pómez, minerales cristalinos revestidos de vidrio, agregados vítreos y materiales vidriosos (Soil Survey Staff 2006). En particular, los suelos desarrollados en áreas adyacentes a los conos volcánicos con una elevada precipitación pluvial y clima frío tienden a acumular vidrio volcánico, material de mayor diámetro y densidad de partícula que el eyectado como ceniza. Si la cantidad de lluvia es suficiente para lavar el Si y las bases (Ca, Mg K y Na) en solución, entonces las propiedades de los suelos se consideran como vítricas (Sieffermann y Millot 1969, Colmet-Daage et ál. 1973, Meijer y Buurman 2003). Debe recordarse que estos suelos tienen un alta porosidad efectiva (45-65\%), moderada conductividad hidráulica $\left(0,02-0,50 \mathrm{~m} \cdot \mathrm{d}^{-1}\right)$ y una distribución de tamaño de poros muy amplia (Foster et ál. 1985).

\section{Definición, características y proceso de formación de las alófanas}

Las alófanas son minerales secundarios comunes en suelos originados a partir de la meteorización de materiales volcánicos en condiciones de buen drenaje y temperatura media (Besoain 1985, Wada 1989, Mizota y van Reeuwijk 1989, Quantin et ál. 1991) que raramente se forman en sitios con muy alta precipitación y temperatura (Sieffermann y Millot 1969) como ocurre en las llanuras aluviales del Caribe de Costa Rica (Meijer y Buurman 2003, Arias et ál. 2010a), en zonas a mucha altura con cenizas volcánicas gruesas recientemente depositadas, o rocas volcánicas fuertemente meteorizadas en clima frío (Colmet-Daage et ál. 1973, Knoblich et ál. 1996, Meijer y Buurman 2003), o a partir de cenizas volcánicas ricas en sílice (Andriese et ál. 1976). Sin embargo, bajo este tipo de condiciones Alvarado (1974) en las faldas del volcán Irazú y Tan et ál. (1975) en la vertiente Caribe del cerro Platanar encontraron alofana en la fracción arcillosa de estos suelos cuya precipitación se ve favorecida a $\mathrm{pH}>5,0$, que describe además, un número importante de fitolitos que se conservan en el suelo después de muerto y mineralizado el tejido vegetal de gramíneas y que estabilizan la sílice y aumentan las fracciones cristalinas y no cristalinas del suelo (Kelly et ál. 1998).

Basándose en la relación Al:Si y desde un punto de vista operacional, las alofanas ocurren en una serie con 2 miembros terminales; los miembros de la serie ricos en $\mathrm{Al}(\mathrm{Al}: \mathrm{Si}=2: 1)$ y los ricos en $\mathrm{Si}(\mathrm{Al}: \mathrm{Si}=1: 1)$. Las alófanas ricas en $\mathrm{Al}$ (también llamadas alofanas tipo proto-imogolita o similares a la imogolita) se relacionan con la imogolita por tener el mismo arreglo atómico y composición química (Al:Si=2:1); sin embargo difieren morfológicamente y se considera que provienen de fragmentos con el mismo arreglo estructural y composición química de la estructura de la imogolita por un período de tiempo corto (Parfitt y Henmi 1980). Besoain (1985) resume a varios autores que reconocen la existencia de la alófana A (que consideran como la más común) y presenta una proporción similar de Si y Al, la alófana tipo B que es rica en sílice y la alófana tipo $\mathrm{C}$ que es rica en aluminio y la más común en suelos viejos de baja fertilidad.

Las principales propiedades de la alófana son: (1) una superficie específica mayor de 500 $\mathrm{m}^{2} \mathrm{~g}^{-1}$, (2) una elevada capacidad de intercambio aniónico (CIA) con (3) una alta capacidad de retener fosfatos y zinc, (4) una capacidad de intercambio de cationes (CIC) alrededor de 100 $\operatorname{cmol}(+) \cdot l^{-1}$ de arcilla, la cual es dependiente del 
pH por tener carga variable, (5) el 50\% de la carga ocurre en los tetraedros de $\mathrm{Al} / \mathrm{Si}$ y el otro $50 \%$ se da por sustitución isomórfica, 6) baja densidad aparente, 7) secado irreversible y baja dispersabilidad y 8) alta porosidad (Andriesse et ál. 1976, Foster et ál. 1985, Porta et ál. 2003). En la Figura 8 se muestra la falta de reflexiones en el difractograma de rayos $\mathrm{X}$ dada la baja cristalinidad de este material, así como los picos exotérmicos y endotérmicos en el análisis térmico por pérdida de agua e hidroxilos que la caracterizan y su forma amorfa en el microscopio electrónico.

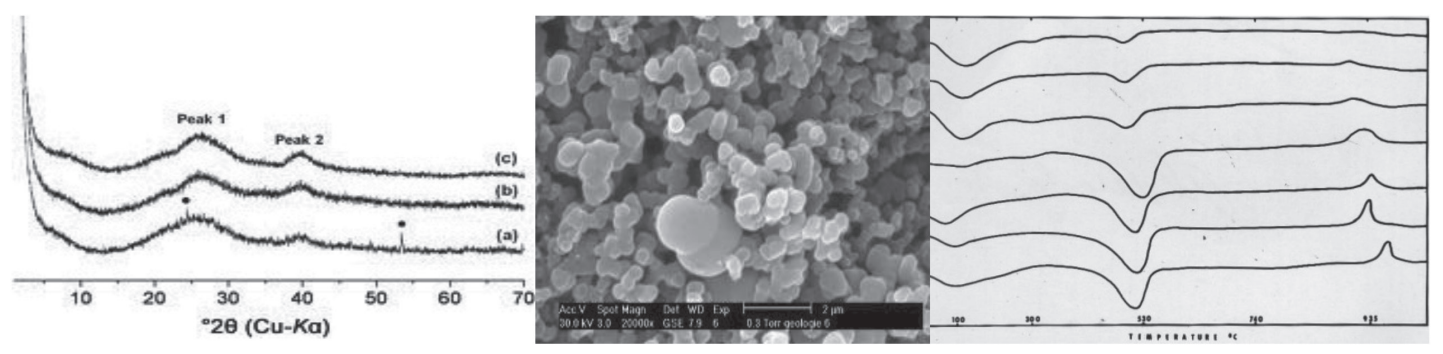

Fig. 8. Difractograma de rayos X, microscopia electrónica y análisis térmico diferencial de arcillas amorfas conocidas como "alofanas" (tomado de Alvarado 1974).

Cuando recién se iniciaba el movimiento de definición del orden de los Andisoles, se propuso que el proceso que conlleva a su formación podía reconocerse como andolización (Sáenz
1969), término que implica la formación de complejos de Al-humus además de la alofanización definida por Besoain (1972) como la formación de alófana de acuerdo con la siguiente ecuación:

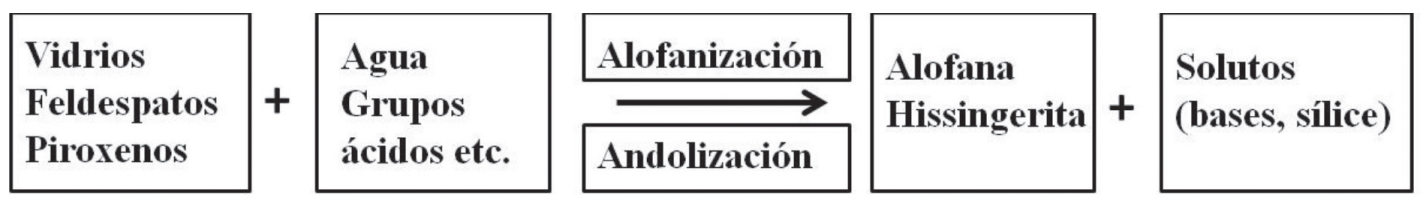

Las propiedades ándicas del suelo se forman comúnmente durante la meteorización de tefras u otros materiales parentales que contienen cantidades significativas de vidrio volcánico y representan una etapa de transición donde la meteorización y la transformación de alúminosilicatos primarios (por ejemplo, vidrio volcánico) ha llegado al punto de formar materiales de baja cristalinidad como alófana, imogolita, ferrihidrita o complejos metálico-húmicos. Las cantidades relativas de alófana, imogolita, ferrihidrita o complejos metal-humus (cuando el pH
$\mathrm{H}_{2} \mathrm{O}$ es < 5,0) en la fracción coloidal se infieren a partir de análisis de laboratorio de aluminio, hierro y sílice extraídos con oxalato de amonio y a partir de la retención de fosfato. Los edafólogos pueden usar la untuosidad o el $\mathrm{pH}$ en fluoruro de sodio (NaF) $1 \mathrm{~N}$ como indicadores de campo de las propiedades ándicas de suelo (Figura 9).

Zehetner et ál. (2003) mencionan que de acuerdo con varios autores, la alófana y la halloysita son los tipos de arcilla dominantes en los suelos derivados de cenizas volcánicas del mundo, habiéndose sugerido que la halloysita se forma a 


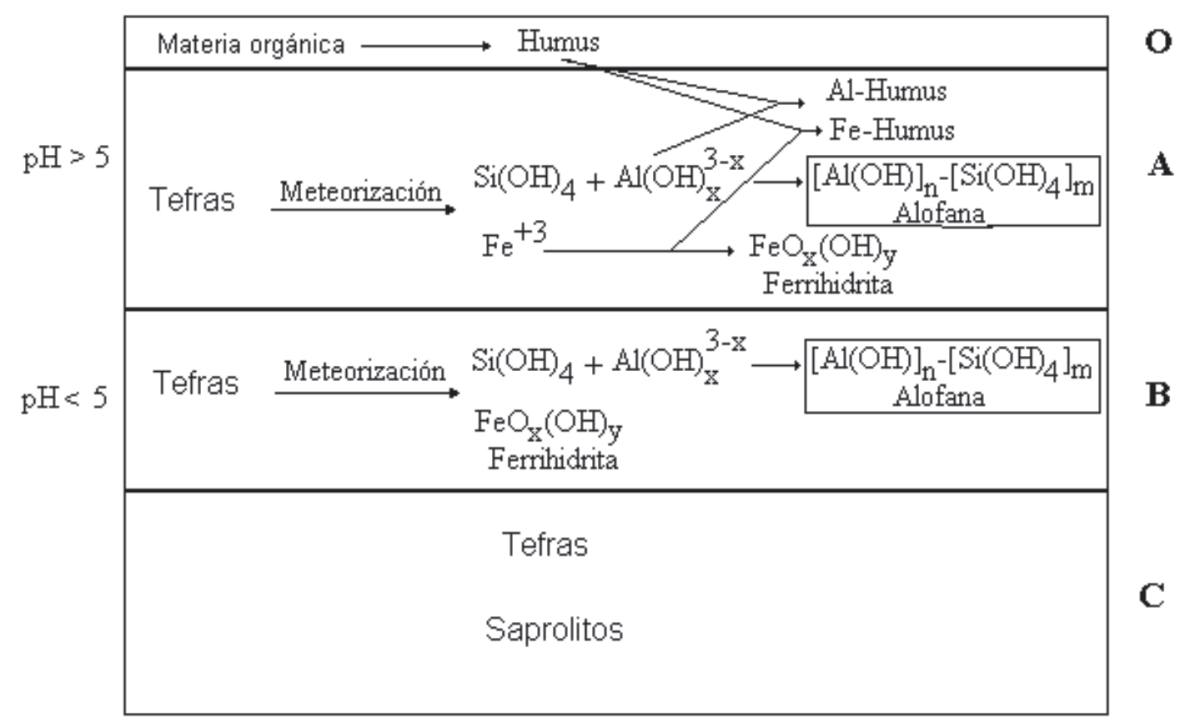

Fig. 9. Proceso de andolización en el suelo (tomado de Zapata 2006).

partir de la meteorización de la alófana aunque se ha demostrado que esta última así como la alófana pueden formarse directamente a partir de la ceniza volcánica, formándose la halloysita cuando la concentración de $\mathrm{H}_{4} \mathrm{SiO}_{4}$ en la solución del suelo excede valores de 250 o $350 \mu$ mol. $^{-1}$ y la alófana a concentraciones inferiores.

\section{Definición, características y proceso de formación de las halloysitas}

La formación de halloysita es el resultado de un enriquecimiento con $\mathrm{Si}$ en condiciones donde el Si en la solución del suelo es $>10 \mathrm{mg} . \mathrm{l}^{-1}$ como resultado de: (1) drenaje deficiente, (2) déficit de humedad en épocas del año o (3) transformación de feldespatos y pseudomorfos pumíceos en microambientes confinados. Las halloysitas pueden presentar una morfología tubular o laminar (Kunze y Bradley 1976) y encontrarse en diferentes grados de hidratación, considerándose que las formas hidratadas son metaestables. El proceso de secado de la halloysita de $1,0 \mathrm{~nm}$ a halloysita de $0,7 \mu \mathrm{m}$, requiere de una serie de pasos progresivos que dependen de la humedad relativa y la temperatura de secado (Figura 10).
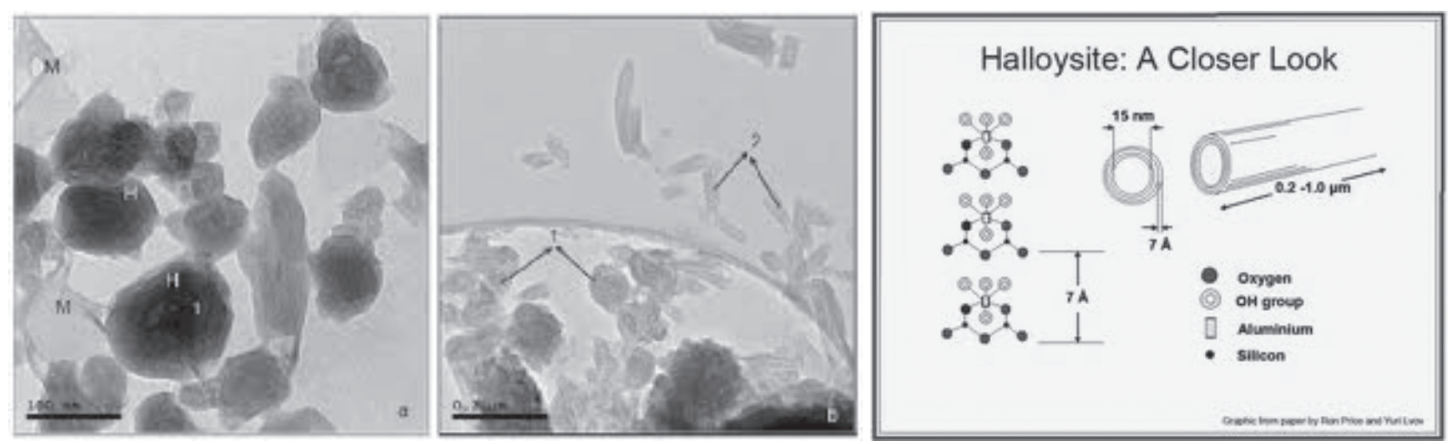

Fig. 10. Fotografías al microscopio electrónico y diagrama de la forma de la halloysita. 
Geológicamente aparecen como masas blancas, a veces teñidas de marrón o amarillo, con fractura concoidal característica y dureza entre $1 \mathrm{a} 2$, con una densidad alrededor de $2,2 \mathrm{~g} \mathrm{~cm}^{-3}$ y en el caso de la halloysita hidratada una CIC que varía entre 10 y $50 \mathrm{cmol}(+) \cdot \mathrm{l}^{-1}$ arcilla (Besoain 1985).

López (1963) identificó a la halloysita como mineral de arcilla dominante en un perfil de San Francisco de Heredia, mientras que Sandoval (2010) ha mencionado la presencia de halloysita hidratada en el horizonte superior de un Typic Hapludults y de un Andic Dystrudepts, el último con características ándicas en el horizonte A asociadas a valores de densidad aparente del suelo menores de $0,67 \mathrm{Mg} \cdot \mathrm{m}^{-3} \mathrm{y}$ pH en $\mathrm{NaF}$ en el rango 9,6-10,7. Aunque no mencionada en la literatura, la presencia de grietas que se cierran periódicamente en los suelos anteriormente mencionados indica que este tipo de arcilla puede tener capacidad de contracción y dilatación o que en los mismos coexiste una cierta cantidad de arcillas expansibles que modifican su reología. Este tipo de arcilla también ha sido reportado en la región noroeste de la finca La Gamba en el Pacífico Sur del país (Scheucher et ál. 2008) donde probablemente se deriva de la meteorización de pequeñas cantidades de cenizas volcánicas depositadas por el volcán Barú según la distribución de estos materiales propuesta por Sherrot et ál. (2008).

\section{Secuencias de formación de arcillas en las cenizas volcánicas en Costa Rica}

Los cambios químicos que ocurren en las cenizas recién depositadas dependen de las condiciones de meteorización y de las propiedades originales del material que da lugar por consiguiente a la formación de diferentes tipos de arcilla. Basados en los cambios ocurridos a través del tiempo Colmet-Daage et ál. (1973) delinearon algunas zonas mineralógicas volcánicas en Costa Rica con dominancia de materiales no cristalinos o cristalinos que han sido también investigadas por González et ál. (1972) y Andriesse y Muller (1973). En la mayoría de los Andisoles de Costa Rica se puede encontrar trazas de vermiculita interestratificada, cuarzo, gibbsita y cristobalita (Centro Científico Tropical 1980, Chichilla 2000). En forma generalizada se puede indicar que las tefras meteorizan a geles amorfos de sílice y aluminio, reconocidos actualmente como minerales de corto ámbito de cristalización (antes conocidos como materiales amorfos y que incluyen a la alófana, la himogolita, la ferrihidrita o complejos húmico alumínicos), los que a su vez pueden pasar a metahalloysitas, halloysitas y finalmente cambiar a gibbsita, caolinita o montmorillonita, según las condiciones ambientales. En general las cenizas oscuras tipo andesíticobasáltico contienen mucho más Fe y Mg que las cenizas claras tipo dacítico-riolítico las cuales contienen una mayor cantidad de $\mathrm{Si}$, y las primeras son las más abundantes en Costa Rica. Debe recordarse que debido a la preparación de las muestras de arcilla para los análisis de rayos $\mathrm{X}$ la muestras son tratadas muy energéticamente, como es el caso de la solubilización de nódulos de Fe y Mn que tienen ocluidas arcillas tipo 2:1, tipos de arcilla que no necesariamente corresponden a una secuencia de alteración.

Secuencias a partir de cenizas andesíticas: Alvarado et ál. (2010) mostraron que en el país la meteorización de las cenizas andesíticas conduce a resultados finales diferentes a partir de las condiciones ambientales definidas principalmente por el relieve, el cual a su vez influye en los regímenes de humedad y temperatura del suelo y de la zona de vida (Figura 11). De manera generalizada, en las partes más elevadas (pisos montano alto y sub-alpino, por encima de los 2500 msnm), perhúmedas, frías y cercanas a los conos de deposición de las cenizas, tiende a acumularse vidrio volcánico asociado con pequeñas cantidades de alófana e hisingerita como se ha encontrado en los alrededores de El Empalme y en el Cerro de la Muerte, Talamanca (Landaeta 1977); sin embargo, Knoblich et ál. (1996) mencionan que las rocas y cenizas volcánicas en la misma región siguen 3 secuencias de meteorización: (1) esmectita-alófana-minerales de hierro-feldespatos, (2) esmectitaalófana-metahalloysita-minerales de hierro, (3) 


\begin{tabular}{|c|c|c|c|c|}
\hline & Altura(msnm) & Rég. hum. y temp & Prop. Suelo (región) & Arcilla dominante \\
\hline & $>2.500$ & $\begin{array}{l}\text { Perúdico, } \\
\text { údico } \\
\text { Isomésico }\end{array}$ & $\begin{array}{l}\text { Arenoso (Caribe } \\
\text { Oeste, Talamanca) }\end{array}$ & $\begin{array}{l}\text { Vidrio volcánico, } \\
\text { hisingerita }\end{array}$ \\
\hline & $2.500-1.500$ & $\begin{array}{c}\text { Údico } \\
\text { Isomésico }\end{array}$ & $\begin{array}{l}\text { Negruzcos, franco } \\
\text { limosos }\end{array}$ & $\begin{array}{l}\text { Alofana/gibbsita, } \\
\text { halloysita, } \\
\text { metahalloysita }\end{array}$ \\
\hline \multirow[t]{4}{*}{$\begin{array}{c}\text { Andesítica } \\
\text { (alta en Fe y Mg) }\end{array}$} & $1.500-800$ & $\begin{array}{c}\text { Ústico } \\
\text { Isohipertérmico }\end{array}$ & $\begin{array}{c}\text { Pardo-amarillentos, } \\
\text { franco-franco } \\
\text { arcillosos }\end{array}$ & $\begin{array}{c}\text { Alofana, } \\
\text { halloiyita/metahalloysita, } \\
\text { gibbsita, ferrihidrita- } \\
\text { goethita-caolinita }\end{array}$ \\
\hline & $800-200$ & $\begin{array}{c}\text { Ústico } \\
\text { Isohipertérmico }\end{array}$ & $\begin{array}{l}\text { Pardo-rojizos, } \\
\text { arcillosos }\end{array}$ & $\begin{array}{l}\text { Halloysita, } \\
\text { metahalloysita, } \\
\text { caolinita }\end{array}$ \\
\hline & $<200$ & $\begin{array}{c}\text { Perúdico } \\
\text { Isohipertérmico }\end{array}$ & $\begin{array}{c}\text { Arenosos-franco } \\
\text { arenosos } \\
\text { (Caribeoeste) }\end{array}$ & $\begin{array}{l}\text { Alofana, } \\
\text { metahalloysita, } \\
\text { halloysita }\end{array}$ \\
\hline & & $\begin{array}{c}\text { Ústico } \\
\text { Isohipertérmico }\end{array}$ & $\begin{array}{l}\text { Franco-franco } \\
\text { arcillosos (Paso } \\
\text { Canoas) }\end{array}$ & $\begin{array}{l}\text { Alofana, halloysita, } \\
\text { montmorillonita }\end{array}$ \\
\hline
\end{tabular}

Fig. 11. Formación de arcillas a partir de cenizas andesíticas en Costa Rica.

alófana-metahalloysita-feldespatos. En las cimas de los volcanes Irazú-Turrialba (Besoain 1972, Colmet-Daage et ál. 1973, Forsythe y Vásquez 1973, Alvarado y Buol 1975, Soto 1998) y PoásBarva (Gómez et ál. 1981, Grieve et ál. 1990, Meijer y Buurman 2003) por un proceso conocido como redistribución de plasma, el Fe disuelto y probablemente acomplejado con materia orgánica en ocasiones puede transferirse a los horizontes inferiores del perfil, donde llega a formar capas delgadas y endurecidas conocidas como horizontes plácicos (Figura 12) como ha sido observado en los alrededores del volcán Irazú (Alvarado
1974), Talamanca (Otárola y Alvarado 1977) y en la cuenca alta del río Pirrís (Chinchilla et ál. 2010b). En Ecuador Zehetner et ál. (2003) describen una secuencia similar, excepto porque no describen los suelos con alto contenido de vidrio volcánico, en la que sobre los $3200 \mathrm{msnm}$ la fracción coloidal está dominada por materiales amorfos en Andisoles con epipedón melánico, entre 3200-2700 msnm coexisten la alófana y la halloysita en Andisoles con epipedón úmbrico y a alturas menores a los $2700 \mathrm{msnm}$ la fracción coloidal está dominada por halloysita en Inceptisoles y Entisoles. 


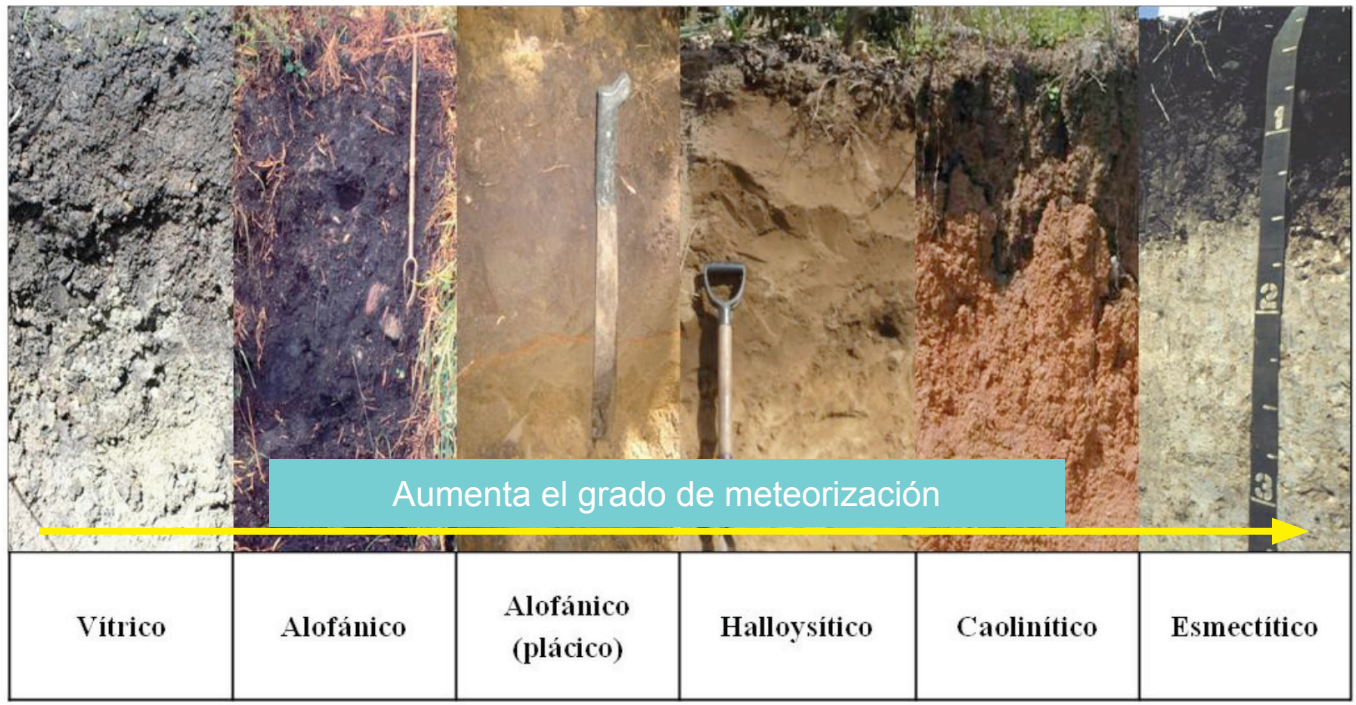

Fig. 12. Secuencia de formación de las principales mineralogías de Andisoles de Costa Rica. De izquierda a derecha perfiles: vítrico cerca de los cráteres, húmico-alofánico en partes altas de la pendiente, alofánico-plácico partes medias de la pendiente, halloysítico parte media-baja de la pendiente, caolinítico parte baja de la pendiente y esmectítico en depresiones de la parte distal.

En lo discutido anteriormente se asume que la distribución y los cambios pedológicos que ocurren en Costa Rica se dan sobre una deposición de cenizas más o menos uniforme en el terreno y en el tiempo. En Ecuador la clasificación de los suelos derivados de cenizas volcánicas de la Sierra separa los formados a partir de cenizas recientes de los formados a partir de cenizas antiguas (Zeaser et ál. 1988), por lo que la variación mineralógica de arcillas en el perfil del suelo no se considera como parte de la evolución de un mismo material para formar diferentes tipos de arcilla en el relieve, sino más bien como producto de diferentes intensidades de meteorización en materiales de diferente edad en el relieve.

En el piso montano bajo (1500-2500 msnm) donde tienden a acumularse cenizas con elevado contenido de limo, los suelos retienen más humedad y forman complejos órgano-minerales estables en un régimen údico-isomésico. Como resultado de la meteorización tienden a formarse suelos negros ricos en alófana asociada a pequeñas cantidades de imogolita, hisingerita, metahalloysita, vermiculita y vidrio volcánico, así como minerales arcillosos heredados del material parental como la alfa-cristobalita y las plagioclasas (Holdridge et ál. 1971, Besoain 1972, González et ál. 1972, Colmet-Daage et ál. 1973, Andriesse y Muller 1973, Alvarado y Buol 1974, Tan et ál. 1975, Alpízar 1977, Cervantes 1977, López 1978, Gómez 1981, Alvarado 1982, Werner 1984, Herrera 1990, Grieve et ál. 1990, Motavalli et ál. 1995, Soto 1998, Chinchilla 2000). Cuando debajo del horizonte superior se encuentra una ceniza más vieja y alterada por acción hidrotermal (Besoaín 1972) se forman capas de un material grisáceo a ligeramente amarillento rico en gibbsita, como ocurre con la serie Birrisito (Dóndoli y Torres 1954). También suelen encontrarse cantidades significativas de gibbsita en los horizontes superficiales (Colmet-Daage et ál. 1973) donde se asocian con halloysita, mientras que los contenidos de metahalloysita tienden a aumentar con la profundidad de los suelos y en mayor grado en los suelos a menor altura (González et ál. 1972).

En el piso premontano (800-1500 msnm), bajo condiciones ústico-isohipertérmicas, se forman suelos pardo amarillentos ricos en halloysita 
y alófana en el horizonte superior y en los que se pueden encontrar metahalloysita, gibbsita, ferrihidrita, goethita y caolinita en su subsuelo. En terrenos ondulados tiende a dominar la caolinita con goethita en todo el perfil y en zonas depresionales la caolinita se asocia con la esmectita, tal como ocurre en el fondo del valle del Guarco, Coris y en La Chichilla, Cartago (Soto 1998, Mata 2010, comunicación personal).

Entre 200-800 msnm se forman suelos Inceptisoles y Ultisoles pardo rojizos que raramente presentan alófana e hisingerita y en los que tienden a dominar la halloysita, metahalloysita y en menor proporción caolinita y gibbsita. A menos de $200 \mathrm{~m}$ de altura las cenizas andesíticas retrabajadas en regímenes de humedad perúdico-ácuico tienen dominancia de alófanas, metahalloysitas y la halloysita como sucede en el Caribe Noroeste (Jongmans et ál. 1994, Arias et ál. 2010b) ó alófana asociada a imogolita (Jongman et ál. 2000); en el último caso Nieuwenhuyse et ál. (2000) mencionan que el grado de meteorización de los minerales primarios aumenta en el orden minerales opacos, piroxenos, plagioclasas y vidrio volcánico para formar complejos $\mathrm{Al}$ /
Fe-humus en el horizonte superficial, mientras que los materiales no cristalinos se manifiestan más con la profundidad del suelo. La ocurrencia de gibbsita, caolinita y halloysita asociadas en los horizontes inferiores del perfil en la zona noroeste del Caribe se explica en términos de paleoclimas más secos del pasado. Ciertamente si el régimen de humedad del suelo es ústico la mineralogía de la fracción arcilla puede estar dominada por alófana, halloysita y montmorillonita, como acontece cerca de Paso Canoas, frontera con Panamá, o presentarse la montmorillonita como arcilla dominante en Vertisoles formados a partir de depósitos laháricos de cenizas volcánicas en la región de Pozos de Santa Ana (Motavalli et ál. 1995).

\section{Secuencias a partir de cenizas riolíti-} cas: Las cenizas u otros materiales volcánicos de composición riolítica (p. ej. tobas) más relevantes desde el punto de vista edáfico ocurren en la provincia de Guanacaste, aunque algunos afloramientos de tobas riolíticas se observan en el Valle Central y otras regiones del país (Figura 13). Andriese et ál. (1976) encontraron que

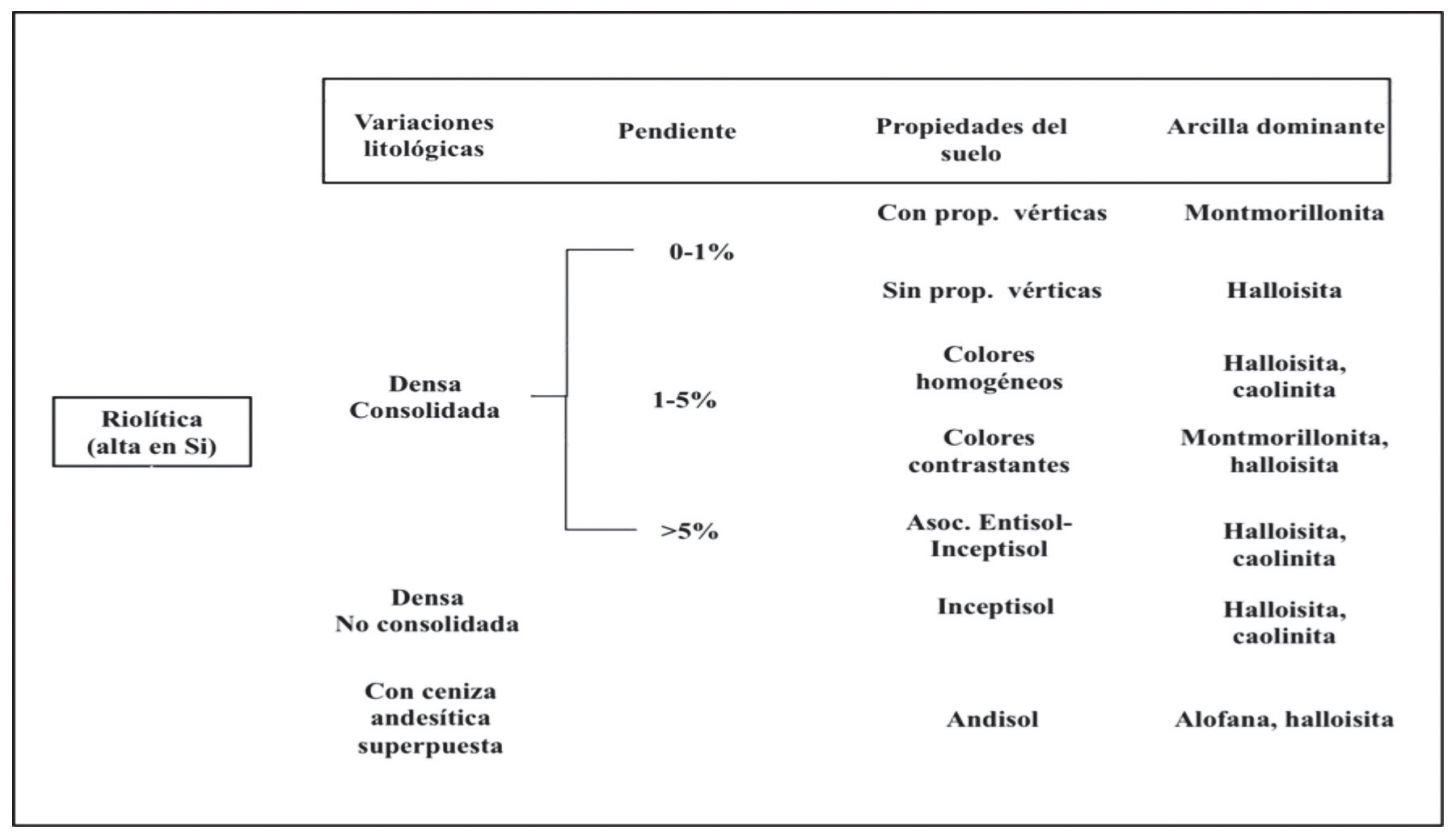

Fig. 13. Formación de arcillas a partir de cenizas riolíticas en Costa Rica. 
la magnitud de retención de $\mathrm{P}$ en el complejo arcilloso de los Andisoles derivados de este tipo de material (fases discretas de geles de $\mathrm{Si} \mathrm{y} \mathrm{Al)}$ presentan una baja capacidad de retención de P. En este ambiente Winters (1997) llevó a cabo un estudio sobre génesis y formación de suelos a partir de este tipo de material donde el el resultado de la meteorización del mismo, depende principalmente del grado de consolidación del material y del tipo y pendiente del relieve; el mismo autor y Mata (1982) mencionan que en algunos casos la adición reciente de cenizas de composición andesítica sobre la toba conduce a la formación de alófana y halloysita, al menos en el horizonte superficial de los suelos de posiciones depresionales.

Aparte del caso antes mencionado Winters (1997) indica que la génesis de los suelos en estos ecosistemas puede llevar a la formación de montmorillonitas en relieves plano cóncavos y de halloysitas en los bordes de las partes depresionales. En relieves ligeramente ondulados, la arcilla dominante es la halloysita, aunque en ciertas condiciones puede encontrarse una acumulación de montmorillonita en el horizonte superior del suelo. En las partes del relieve con más de un 5\% de pendiente, no se forman montmorillonitas y en cambio la arcilla dominante es la halloysita con caolinita en los Inceptisoles y Alfisoles pardorojizos y rojizos más evolucionados. Otros autores, también han encontrado la dominancia de la montmorillonita en las partes depresionales y de halloysita en las pendientes ligeras a su alrededor (USDA-SCS 2012).

Secuencias de mineralogía halloysitacaolinita-gibbsita no derivadas de cenizas volcánicas: Fiskell e Iley (1961) identificaron los minerales de arcilla en 38 suelos de la Meseta Central, de la Zona Atlántica, del Pacífico y de la Zona Sur y encontraron que 29 de los suelos estudiados tenían una mineralogía de corto rango de cristalización dominante, a menudo acompañada por halloysita o caolinita. De manera similar, otros autores han encontrado que la abundancia de alófana en 7 Andisoles de Costa
Rica está acompañada de pequeñas cantidades de caolinita, gibbsita y goethita (USDA-SCS 2012). Kleber et ál. (2007) mencionan el hecho de que no obstante la halloysita y la gibbsita requieren condiciones de formación muy diferentes, es común encontrarlas juntas en Oxisoles derivados de materiales andesíticos en regiones perhúmedas, como sucede en los suelos del Centro de Investigación Biológica La Selva.

La secuencia de formación de halloysita en Humic Haploperox formados sobre materiales andesíticos en regiones perhúmedas de Costa Rica (coladas de lava y depósitos aluviales de composición similar en ambientes perhúmedos) consiste en (1) la rápida disolución de plagioclasas y otros minerales primarios y (2) la transformación pedogenética de halloysita de 10 Å y alófana a halloysita de $7 \AA$ e hidróxidos de $\mathrm{Al}$ amorfos a los rayos $\mathrm{X}$, cambio que parece relacionarse con la edad de los suelos (Kautz y Ryan 2003). En la misma región Kleber et ál. (2007) mencionan que la fracción arcilla de estos suelos está dominada por caolinita y halloysita junto con goethita, hematita, maghemita, cuarzo y cristobalita; los contenidos de caolinita son mayores en los horizontes superiores mientras que los de gibbsita se incrementan con la profundidad del suelo, atribuyendo el fenómeno a una re-silicatación de la gibbsita en superficie por un enriquecimiento con Si producto de una acumulación del mismo por reciclaje de nutrimentos en condiciones de bosque; sin embargo la re-silicatación de la gibbsita se considera termodinámicamente imposible pues la gibbsita ya está cristalinizada y de ella no es posible que se forme un mineral 1:1. Kleber et ál. (2007) al estudiar 2 perfiles de suelo clasificados como Allitic y Mixed Humic Haploperoxs con un régimen de humedad perúdico en el Centro de Investigación Biológica La Selva, mencionan la presencia de caolinita, halloysitas de 1,0 y $0,7 \mu \mathrm{m}$, goethita, hematita, maghemita, cuarzo y cristobalita, además en el perfil más antiguo se encontró gibbsita pura en fragmentos rocosos muy meteorizados con trazas de halloysita $0,7 \mu \mathrm{m}$ y caolinita. 
Bajo regímenes de humedad ústicos Winters (1997) sugiere que el alto contenido de $\mathrm{Si}$ en el vidrio de la ignimbrita de la formación Bagaces, Guanacaste, favorece la formación de arcillas tipo 1:1 como la halloysita y la caolinita y probablemente de algunos minerales no cristalinos. Otros autores (USDA-SCS 2012) encontraron en muestras de 4 perfiles de Mollisoles de la región de Guanacaste abundantes cantidades de halloysita en los horizontes superficiales y menores de cristobalita, goethita y montmorillonita a mayor profundidad.

\section{Factores que afectan la formación de arcillas de corto rango de cristalización y halloysíticas}

\section{Efecto del material parental y del tiem-}

po: La composición química total de las cenizas volcánicas de Costa Rica ha sido estudiada por varios autores (Murata et ál. 1966, Chaves 1969, Lewis et ál. 2006, Reeves et ál. 2007, Pelt et ál. 2008, Scheucher et ál. 2008, Schembre 2009, Ryan y Huertas 2009, Charpantier et ál. 2011), de donde se desprende que el rango de la concentración de $\mathrm{Fe}(5,47-14,02 \%)$ es significativamente más amplio que el de los demás elementos analizados. Asimismo, la cantidad promedio de $\mathrm{Na}$ $(2,67 \%)$ es mayor que la de $\mathrm{K}(1,82 \%)$ y el $\mathrm{P}$ total $(0,16 \%)$ es mucho más elevado que el encontrado en muchos otros tipos de suelo; la alta concentración de $\mathrm{P}$ total en estos suelos se explica con base en su alto contenido de apatita y debida a los fertilizantes (Alvarado y Buol 1985, Ramírez et ál. 2008). Al comparar la composición química total de la ceniza reciente con materiales similares ya meteorizados, se nota una pérdida absoluta de $\mathrm{Si}, \mathrm{Ca}, \mathrm{Mg}$, Na y K y a una acumulación neta de Al, Fe, Ti y P (Bornemisza 1971, Alvarado y Mata 1993).

Efecto del régimen de humedad: La modificación del sistema de clasificación de suelos (Soil Survey Staff 1999) permite separar dentro de los Andisoles aquellos suelos que presentan características vítricas de los que tienen propiedades ándicas. Esta división es importante en el tanto en que Maldonado (1973) en Ecuador, menciona que en regímenes arídicos, ústicos y údicos la mineralogía dominante en Andisoles varía de feldespatos a halloysita a arcillas amorfas, secuencia que en Costa Rica puede observarse parcialmente al comparar los Andisoles de Guanacaste, del Valle Central y de la fila Costanera en la frontera con Panamá. Forsythe y Vásquez (1973) al estudiar 3 Hydric Hapludands notaron que los 2 desarrollados bajo un clima con verano pronunciado, las series Alajuela Plano y Alajuela Ondulado, tenían metahalloysita como mineral dominante, mientras que la serie Birrisito sin época seca bien definida, tenía alófana como mineral dominante.

Efecto de la altitud: La altura no solo modifica los regímenes de temperatura y humedad en el relieve sino que con ellos también la pedogénesis de los suelos, es decir la formación de arcillas minerales y su combinación con sustancias orgánicas. Algunos autores han mencionado que la descomposición de los residuos orgánicos disminuye con la altura desde los 100 hasta los $2000 \mathrm{msnm}$, lo que causa un aumento del contenido de materia orgánica del horizonte A de $18 \%$ a $49 \%$, mientras que la relación $\mathrm{Fe}$ libre/Fe-total decrece de 0,3 a 0,1 (Grieve et ál. 1990). En trabajos de laboratorio y campo Herre et ál. (2007) estudiaron los mecanismos de tamponamiento ácido y la formación de minerales secundarios en Andisoles vítricos de las laderas de los volcanes Masaya en Nicaragua y Poás en Costa Rica los cuales expelen cantidades considerables de lluvias ácidas. En el caso de Costa Rica encontraron un mecanismo de tamponización a corto plazo, que consiste en la disolución de los cristales de plagioclasas y la protonación de grupos carboxílicos y otro de largo plazo en el cual se disuelven las plagioclasas pero no llegan a protonarse con la materia orgánica. Bajo las condiciones perúdicas del volcán Poás el Al parece ser susceptible al lavado y la tamponización ácida resulta en la formación de sílica amorfa. Los autores mencionan que bajo las condiciones perúdicas del volcán Poás el aluminio producto de la meteorización es susceptible a lavarse y que 
la tamponización ácida resulta en la formación de sílica amorfa, lo que es poco probable pues el $\mathrm{Al}$ en Andisoles se acompleja con el humus para formar ópalo.

Efecto de la cobertura vegetal: En sitios a más de 2200 msnm, Harris (1971b) describió la presencia de Espodosoles desarrollados sobre cenizas volcánicas en la Cordillera de Talamanca y en un trabajo posterior en la misma región Landaeta et ál. (1978) describen otro Espodosol en el cual la arcilla dominante en todo el perfil es la alófana, asociada a cantidades significativas de otros materiales de corto rango de cristalización, arcillas 1:1 y trazas de hisingerita. Blaser (1990) menciona que en esta misma región los Placudands dominan bajo vegetación de bosque de una mezcla de robles mientras que los Hapludands dominan bajo el bosque de roble blanco. La diferencia entre estos 2 tipos de suelos consiste en la presencia de un "horizonte plácico", o capa dura, continua y delgada formada por movimiento preferente de Fe quelatado por sustancias orgánicas producidas por el roble y que llega a impedir el drenaje. La influencia de Quercus costaricensis y Chusquea tormentosa sobre la formación de los suelos de la cordillera de Talamanca también ha sido documentada por Widmer (1999) y recientemente por Chinchilla et ál. (2011b). No obstante lo arriba mencionado, debe recordarse que explicar la formación de horizontes espódicos en suelos derivados de depósitos de ceniza volcánica no es fácil, en especial donde predomina la alofana que no permite la quimio-iluviación de Al y donde el Fe es precipitado como ferrihidrita.

La mayoría de los Andisoles de la cordillera de Guanacaste presentan mineralogía de arcillas de corto rango de cristalización y según el grado de desarrollo del perfil trazas de vermiculita interestratificada o caolinita y gibbsita (Centro Científico Tropical 1980). Los Andisoles desarrollados sobre ignimbritas son el producto de la meteorización de cenizas andesíticas sobrepuestas y presentan una dominancia de materiales amorfos sobre caolinita y esmectitas formadas a partir de la toba (Winters 1997). La formación de caolinita y esmectitas en el material parental de la caldera del volcán Miravalles se menciona como factible a cierta profundidad y bajo efecto hidrotermal (Rochelle et ál. 1989).

Efecto del relieve: Los suelos derivados de cenizas volcánicas más estudiados de Costa Rica, se encuentran en los macizos Poás-Barva e Irazú-Turrialba. En la primera situación se menciona con frecuencia las series Arenón Poasito, Alajuela Plano, Alajuela Ondulado y Grecia, las cuales se encuentran en secuencia de la parte más alta a la parte más baja del relieve. Similarmente, en los volcanes Irazú-Turrialba se describen las series Irazú, Cervantes, Birrisito y Colorado. En las series de suelos Alajuela Ondulado y Grecia se encontró un alto contenido de alófana pero los rayos X muestran una cantidad moderada de gibbsita y de halloysita en menor cantidad. Del trabajo de Colmet-Daage et ál. (1973) se concluye que en las partes altas del relieve dominan materiales amorfos mientras que en las partes medias son más comunes la halloysita y la gibbsita en una matriz amorfa. El fenómeno de cristalización quizá se vea favorecido por la presencia de un régimen de lluvia seco-húmedo en la última zona.

González (1972) determinó la composición mineralógica de una catena de suelos con un primer componente en el volcán Irazú y hasta llegar a la serie Birrisito en su punto más bajo. En la secuencia se encontró que los siguientes materiales determinan las propiedades de estos suelos: en la parte alta cenizas recientes, en las regiones medias geles discretos con alófana y metahalloysita en la parte distal. En el mismo edificio volcánico Besoain (1972) encontró que en la fracción de arcilla de las series Irazú, Cervantes y Birrisito dominan la alófana, aunque con abundante presencia de gibbsita en ésta última. Este comportamiento se explica por la presencia de cenizas uniformes y permeables al agua, creándose un ambiente bastante constante que favorece las reacciones de "andosolización" sensu Sáenz y Alvarado (1980).

Colmet-Daage et ál. (1973) identificaron en los flancos de los volcanes Turrialba e Irazú 
varios Hydrudands alofánicos y en un perfil de la vertiente norte alofánico observaron la presencia de gibbsita en forma de pequeñas concreciones. Los mismos autores encontraron que entre Pacayas y Cervantes ocurre una transición de suelos que comienza con alófana en las partes altas de la pendiente a otros con halloysita; con un contenido de gibbsita, detectable en una proporción mayor en la superficie que a mayor profundidad en una matriz alofánica en las partes más bajas del relieve.

Aunque la información sobre Andisoles en terrenos aluviales de la Zona Norte y Atlántica es escasa, Werner (1984) informó sobre alófana en abundancia, acompañada por caolinita y halloysita en un Andisol de Centro de Investigación Biológica La Selva. En los lahares del flanco atlántico del volcán Turrialba, van Dooremolen et ál. (1990) encontraron pocas arcillas cristalinas en una matriz alófanica con complejos Al-humus; los suelos más desarrollados presentaron un aumento de Al-humus y de halloysita. Arias et ál. (2010a) discuten la formación de arcillas derivadas de cenizas volcánicas en la región noroeste del Caribe donde las arcillas dominantes son metahalloysitas.

Aparte de los suelos descritos en las laderas de los volcanes, varios autores (Jongmans et ál. 1995, Nieuwenhuyse et ál. 1993, Nieuwenhuyse et ál. 1994, Nieuwenhuyse 1996, Stoorvogel y Eppink 1995, Nieuwenhuyse y van Breemen 1997, Arias et ál. 2010a) mencionan la presencia de alófanas en suelos ubicados al noroeste de la subcuenca Vueltas-Silencio-Parismina en la región del Caribe, considerándose que estas se forman en otros sitios y se transportan vía fluvial hasta las llanuras aluviales. Bajo condiciones perhúmedas en la zona Caribe de Costa Rica, Buurman et ál. (1997) mencionan que la meteorización de las cenizas volcánicas en las laderas no permite la formación de materiales amorfos en las partes altas debido al exceso de lixiviación y las texturas arenosas; sin embargo, los materiales amorfos dominan en las laderas medias del piso montano y en la parte distal de las laderas solo llegan a formarse halloysitas y metahalloysitas.
Van Dooremolen et ál. (1990) y Nieuwenhuyse y van Breemen (1997) mencionan que en los Andisoles más recientes desarrollados sobre lahares en las llanuras del Caribe, los suelos se caracterizan por una baja proporción de arcillas cristalinas y preponderancia de alófana sobre complejos de Al-humus en el horizonte A; los mismos autores consideran que en los suelos de más de 2000 años se incrementa el contenido de complejos órganominerales en el horizonte A y la formación de halloysita y gibbsita y óxidos e hidróxidos de $\mathrm{Fe}$ y Al a expensas de la alófana en el horizonte B.

Al discutir la mineralogía de los suelos derivados de coladas de lava andesítica del Pleistoceno y de terrazas aluviales en las planicies del Holoceno del Centro de Investigación Biológica La Selva, Kautz y Ryan (2003) mencionan que ambos suelos están dominados por halloysita asociada a cantidades pequeñas de alófana, producto de la meteorización de plagioclasas. Buurman et ál. (1997) mencionan que la meteorización de las cenizas volcánicas de las llanuras del Caribe se ve fuertemente afectada por la cantidad de precipitación pluvial de la zona, la frecuencia (edad) con que se depositan las cenizas y la disminución de la temperatura del suelo con la elevación, factores que favorecen una mayor meteorización en los suelos de las zonas más bajas. La cantidad y el tamaño de los agregados de alófana en la zona (2 a $20 \mu \mathrm{m}$ ) aumentan con la profundidad del suelo, excepción hecha de las discontinuidades litológicas presentes en la mayoría de los perfiles analizados. Al estudiar los cambios químicos sufridos en una catena de suelos en la falda sur del volcán Turrialba, Meijer y Buurman (2003) encontraron que basados en el patrón de lavado de Mg ocurren 3 procesos: (1) pérdida rápida por lavado preferencial de cationes en áreas cercanas al cráter, sin formación de alófana, (2) formación subsecuente de alófana a elevaciones entre 660 y 1220 msnm y (3) pérdida por lavado a largo plazo de óxidos básicos (pero no de sílice) durante el envejecimiento de los sedimentos fluvio-volcánicos en la llanura aluvial a menos de $240 \mathrm{msnm}$. Sin embargo, Pringle et ál. $(1986,1990,1993)$ indican que las aguas sub-superficiales ricas en fósforo y 
bases disueltas afloran a través de acuíferos sobre basaltos a lo largo de fallas geológicas o en el piedemonte, donde coinciden la cadena de montañas y la llanura aluvial, de manera que también pueden encontrarse algunos suelos de fertilidad media en esta última región.

\section{Efectos de la formación de horizontes:}

En los Andisoles de Centroamérica, Martini (1969) menciona que el contenido de alófana es apreciablemente mayor en los horizontes A (23$78 \%)$ que en los horizontes B (16-26\%), fenómeno atribuido a la mayor edad de los horizontes subsuperficiales (Alvarado y Buol 1974) y según Alvarado y Mata (1993) acompañado por una pérdida neta de Si con acumulación de Fe y Al. Algo similar encontraron Ndayiragije y Delvaux (2003) en el horizonte Bw de un Andisol formado a partir de cenizas andesítico-daciticas en la isla de Guadalupe, Antillas Francesas, en el cual la fracción arcilla consiste de gibbsita, caolinita y arcillas 2:1 hidroxialúminico-interestratificadas, las 3 primeras ligadas a un lavado intenso de sílice.

Andriesse y Muller (1973) analizaron la fracción de arcilla de 2 perfiles de la serie Birrisito. En uno de ellos el mineral principal es la alófana y solamente el horizonte A12 contiene una cantidad apreciable de gibbsita; en el otro perfil, tanto la alófana como la gibbsita son componentes importantes en todos los horizontes y aumentan con la profundidad, este último aspecto atribuido por Besoain (1985) a un efecto hidrotermal en la región. En los suelos volcánicos de la Zona Sur, López (1978) observó la dominancia de materiales amorfos, especialmente la alófana y sugirió la posible presencia de hisingerita y de pequeñas cantidades de un mineral 1:1, posiblemente halloysita o metahalloysita. A mayor elevación, en la cordillera de Talamanca, Landaeta et ál. (1978) encontraron como mineral dominante la alófana con otros materiales amorfos poco comunes; además, identificaron hisingerita en la mayoría de los horizontes y dominancia de arcilla 1:1 en el horizonte BC de uno de los perfiles, posiblemente halloysita.

\section{AGRADECIMIENTOS}

A los Drs. Raúl Zapata, Juan C. Loaiza, José Torrent y Lolita Campos y revisores anónimos por sus comentarios y recomendaciones sobre el presente trabajo. De la misma manera se extiende el agradecimiento a los Ings. Jesús Fernández, Wellins Durango y Oldemar Vargas por su ayuda en la revisión de los borradores del documento y a la Asociación Costarricense de la Ciencia del Suelo por el financiamiento parcial que permitió la contratación de D'Angelo Sandoval Chacón, a quien se agradece la colaboración en el manejo de la base de datos y la confección de los mapas.

\section{LITERATURA CITADA}

ALPÍZAR L. 1977. Caracterización de las fracciones arena, arcilla y determinación del ZPC de cuatro perfiles de suelos ubicados entre los volcanes Poás y Barva. Tesis de Ingeniero Agrónomo, Universidad de Costa Rica, San José, Costa Rica. 99 p.

ALVARADO A. 1974. A volcanic ash soil toposequence in Costa Rica, Central America. Thesis M.Sc., N.C. State University, Raleigh,North Carolina. 89 p.

ALVARADO A. 1982. Phosphate retention in Andepts from Guatemala and Costa Rica as related to other soil properties. Thesis Ph.D., N.C. State University. Raleigh, North Carolina. $82 \mathrm{p}$.

ALVARADO A. 1984. Aluminio activo en suelos derivados de cenizas volcánicas de Costa Rica y Guatemala. Turrialba 34(3):396-398.

ALVARADO A., BUOL S.W. 1974. A volcanic ash toposequence in Costa Rica. Soil Science Society America Proceedings 39:932-937.

ALVARADO A., BUOL S.W. 1985. Field estimation of phosphate retention by Andepts. Soil Science Society America Proceedings 49(4):911-914.

ALVARADO A., MATA R. 1993. Análisis químico total de suelos por espectrometría de fluorescencia de rayos X. In: IX Congreso Nacional Agronómico y de Recursos Naturales. San José, Costa Rica. Vol. II-(2):230.

ALVARADO A., BERTSCH F., BORNEMISZA E., CABALCETA G., FORSYTHE W., HENRIQUEZ C., MATA R., MOLINA E., SALAS R. 2010. Suelos derivados de cenizas volcánicas (Andisoles) de Costa Rica. Asociación Costarricense de la Ciencia del Suelo. San José, Costa Rica. 122 p.

ALVARADO G.E. 2000. Volcanes de Costa Rica. 2a. ed. EUNED. San José, Costa Rica. 269 p. 
ANDERSON M.S., BYERS H.G. 1931. Character of the colloidal materials in the profiles of major soil groups of the United States. U.S. Dept. Agr. Tech. Bull. 228 p.

ANDRIESSE J.P., MULLER A. 1973. Mineralogical properties of two profiles of volcanic ash soil from Costa Rica. Turrialba 23(3):303-317.

ANDRIESSE J.P., ROSMALEN H.A. van, MULLER A., 1976. On the variability of amorphous materials in Andosols and their relationships to irreversible drying and P-retention. Geoderma 16:125-138.

ARIAS F., ALVARADO A., MATA R., SERRANO E., LAGUNA J. 2010c. Relación entre la mineralogía de la fracción arcilla y la fertilidad de algunos suelos cultivados con banano en las llanuras aluviales del Caribe de Costa Rica. Agronomía Costarricense 34(2):223-236.

ARIAS F., MATA R., ALVARADO A., SERRANO E., LAGUNA J. 2010a. Caracterización química y clasificación taxonómica de algunos suelos cultivados con banano en las llanuras aluviales del Caribe de Costa Rica. Agronomía Costarricense 34(2):177-195.

ARIAS F., MATA R., ALVARADO A., SERRANO E., LAGUNA J. 2010b. Mineralogía de la fracción arcilla de algunos suelos cultivados con banano en las llanuras aluviales del Caribe de Costa Rica. Agronomía Costarricense 34(2):197-222.

BARQUERO J., SÁENZ R. 1987. Aparatos volcánicos de Costa Rica. Observatorio Vulcanológico y Sismológico de Costa Rica. Universidad Nacional. Heredia, Costa Rica. (mapa escala 1:750.000).

BARTO-KYRIAKIDIS A. 1989. Weathering processes and products and deposits. THEOPHRASTUS Publications A.E. Grecia. Vol 1: 462 p. y Vol 2: $671 \mathrm{p}$.

BERRANGÉ J.P., MATHERS S.J., MORALES N., ALVARADO F. 1990. The non-metallic industrial minerals and rocks of Costa Rica. Proyecto AngloCostarricense de Minerales Industriales (PACOMI). Direc. Geol. Min. Hidroc., British Geol. Surv./ RECOPE. Informe Interno. San José, Costa Rica. $181 \mathrm{p}$.

BERTOLANI M., LOSCHI-GHITTONI A.G. 1986. Clay minerals from the Central Valley of Costa Rica and their possible ceramic uses. Applied Clay Science 1:239-254.

BESOAIN E. 1985. Mineralogía de arcillas de suelos. San José, CR, IICA. 1216 p. Serie de Libros y Materiales Educativos; No.60. 1205 p.

BESOAIN E. 1972. Mineralogía de arcillas de algunos suelos volcánicos de Costa Rica, pp. 249-278. In: M. Blasco y R. Guerrero (eds.). II Panel sobre suelos volcánicos de América. Univ. de Nariño-IICA-OEA. Pasto, Colombia.
BIRKELAND P.W. 1984. Soil and geomorphology. Oxford University Press. Inc. N. Y. 372 p.

BLASER J. 1990. Estructura, composición y aspectos silviculturales de un bosque nublado de robles (Quercus spp.) del piso montano de Costa Rica. Proyecto CATIE/COSUDE, Silvicultura de Bosques Naturales. Turrialba, Costa Rica. 241 p.

BORNEMISZA E. 1971. Extraction of anions and cations from recent volcanic ash. Soil Science Society America Proceedings 35(3):506-507.

BORNEMISZA E. 1969. Minerales de arcilla en suelos centroamericanos y de Panamá. Turrialba 19(1):97102.

BORNEMISZA E., IGUE K. 1967. Óxidos libres de hierro y aluminio en suelos tropicales. Turrialba 17(1):23-30.

BORNEMISZA E., PINEDA P. 1969. Minerales amorfos y mineralización de nitrógeno en suelos derivados de cenizas volcánicas. In: Panel sobre Suelos Derivados de Cenizas Volcánicas de América Latina. Centro de Enseñanza e Investigación del IICA. Turrialba, Costa Rica. B.7.1-7.7.

BUURMAN P., DE BOER K., PAPE T.H. 1997. Laser diffraction grain-size characteristics of Andisols in perhumid Costa Rica: the aggregate size of allophane. Geoderma 78:71-91.

CAMPOS E. 1997. Simulación de la dispersión de ceniza durante las erupciones de noviembre de 1995 del volcán Rincón de la Vieja. Tópicos Meteorología Oceanografía 4(1):5-13.

CANESSA J., SANCHO F., ALVARADO A. 1986. Retención de fosfatos en Andepts de Costa Rica. I. Relaciones entre la retención de fosfatos, el pH en $\mathrm{NaF}$ y el aluminio activo. Turrialba 36(4):431-438.

CÁRDENES G. 2003. Caracterización de los materiales sedimentarios inconsolidados costeros y aluviales actuales en la región de Parrita, Pacífico Central, Costa Rica. Revista Geológica de América Central 29:63-65.

CASTILLO R. 1997. Recursos minerales de Costa Rica: génesis, distribución y potencial. Editorial de la Universidad de Costa Rica. San José, Costa Rica. $221 \mathrm{p}$.

CENTRO CIENTÍFICO TROPICAL. 1980. Estudio ecológico integral de las zonas de afectación del Proyecto Arenal. Informe Final, ICE. San José, Costa Rica. 388 p.

CERVANTES C. 1977. Caracterización de la fracción mineral y determinación del ZPC en cuatro Andepts de la provincia de Guanacaste. Tesis de Ingeniero Agrónomo. Universidad de Costa Rica, San José, Costa Rica. 78 p.

CHAVES R. 1969. Características físicas, químicas y mineralógicas de los materiales eruptados por el volcán Arenal (Costa Rica). Inst. Geogr. Costa Rica. Informe Semestral enero-junio. pp. 49-67. 
CHIESA S. 1991. El flujo de pómez biotítico del Río Liberia (Guanacaste) Costa Rica, América Central. Revista Geológica de América Central 13:73-84.

CHINCHILLA M. 2000. Estudio mineralógico, físicoquímico y clasificación de los suelos del Proyecto Hidroeléctrico Cariblanco (Alajuela-Costa Rica). Tesis Ingeniero Agrónomo. UNA. Heredia, Costa Rica. 154 p.

CHINCHILlA M., ALVARADO A., MATA R. 2011a. Factores formadores y distribución de suelos de la subcuenca del río Pirris, Talamanca, Costa Rica. Agronomía Costarricense 35(1):33-57.

CHINCHILLA M., MATA R., ALVARADO A. 2011b. Caracterización y clasificación de algunos Ultisoles de la región de Los Santos, Talamanca, Costa Rica. Agronomía Costarricense 35(1):59-81.

CHIRINOS H.A. 1957. Levantamiento agrológico de la Estación Experimental Agrícola de la Universidad de Costa Rica. Tesis de Ingeniero Agrónomo, Universidad de Costa Rica. San José, Costa Rica. $107 \mathrm{p}$.

CLARK S.K., REAGAN M.K., TRIMBLE D.A. 2006. Tephra deposits for the past 2.600 years from Irazú volcano, Costa Rica. Geological Society of America. Special Paper $\mathrm{N}^{\circ}$. 412. pp. 225-236.

COLMET-DAAGE F., MALDONADO F., de KIMPE C., TRICHET M., FUSIL G. 1973. Caracteristiques de quelques sols derives de cendres volcaniques de la Cordillere Central du Costa Rica. Ed. prov. Office de la Recherche Scientifique et Technique Outre-Mer, Centre des Antilles, Bureau des Sols. Guadalupe. $32 \mathrm{p}$.

DÓNDOLI C. 1943. La región de El General, condiciones geológicas y geoagronómicas de la zona. Departamento Nacional de Agricultura. Boletín Técnico 44. $16 \mathrm{p}$.

DÓNDOLI C. 1950. Suelos de la zona de Palmares. Suelo Tico 4(21-22):260-262.

DÓNDOLI C., TORRES J.A. 1954. Estudio geoagronómico de la región oriental de la Meseta Central. San José, Costa Rica, Ministerio de Agricultura e Industria. $180 \mathrm{p}$.

DROSDORFF M., PEARSON R.W. 1951. Soil and leaf analysis in relation to abaca production in Central America. IICA. Abaca Research Report No. 5. 25 p.

FISHER G.B., RYAN P.C. 2006. The smectite-to-disordered kaolinite transition in a tropical soil chronosequence, Pacific Coast, Costa Rica. Clays and Clay Minerals 5:571-586.

FISKEL J.G.A., ILEY J.R. 1961. Report on the clay fraction of Costa Rican soils. University of Florida. Mimeo Report. USA. 5 p.

FORSYTHE W.M. 1972. Proposed techniques to avoid the effect of air-drying on the water retention of soils derived from volcanic ash, pp. 481-496. In: II
Panel sobre Suelos Volcánicos de América, Univ. de Nariño-IICA-OEA. Pasto, Colombia.

FORSYTHE W., VÁSQUEZ M.O. 1973. Effect of air-drying on the water retention curves of disturbed samples of three soils of Costa Rica derived from volcanic ash. Turrialba 23(2):200-207.

FOSTER S.S.D., ELLIS A.T., LOSILLA M., RODRÍGUEZ V. 1985. Role of volcanic tuffs in ground-water regime of Valle Central, Costa Rica. Ground Water 23(6):795-801.

GÓMEZ O. 1981. Suelos volcánicos de Costa Rica y su aptitud para el cultivo de café, Tesis de doctorado. Universidad Amistad de los Pueblos Patricio Lumumba, Moscú.188 p.

GÓMEZ O., CHINCHILLA M. 2005. Estudio taxonómico y mineralógico de los suelos de la cuenca del río Térraba a escala 1:50.000, provincias de Puntarenas y San José. MAG/ICE. San José, Costa Rica. 226 p.

GÓMEZ O., CHERNYAKHOVSKY N., CHIZHIKOVA N.P., SHURYGINA E.A., GRADUSOV B.P. 1981. Mineralogical composition of volcanic soils in Costa Rica tropics. Tesis Doctoral, Universidad de Moscú. (original en ruso). Moscú, Rusia. 135 p.

GONZÁLEZ S.P., IGUE K., BESOAIN E. 1972. Secuencia de meteorización y su relación con las propiedades de carga y superficie de la fracción arcilla de algunos andosoles de Costa Rica. Turrialba 22(4):439-448.

GONZÁLEZ S.P. 1972. Caracterización de la fracción arcilla en algunos suelos derivados de cenizas volcánicas de Costa Rica. Tesis M.S. IICA-CATIE, Turrialba, Costa Rica. 78 p.

GRIEVE I.C., PROCTOR J., COUSINS S.A. 1990. Soil variation with altitude on Volcán Barba, Costa Rica. Catena 17(6):525-534.

HARDMAND J.M., ÁVILA H., OLIVER R., SINT-ANDRÉ L., DAMBRINE E. 2010. The impact of kaolinite and oxi-hydroxides on nitrate adsorption in deep layers of a Costarrican Acrisol under coffee cultivation. Geoderma 158:216-224.

HARDY F., BAZÁN R. 1963a. Studies in Costa Rican soils (I) Senile latosol (Colorado Series). (A) Genesis, mineralogical and chemical composition. Inter-American Institute of Agricultural Sciences. Turrialba, Costa Rica. 8 p.

HARDY F., BAZÁN R. 1963b. Studies in Costa Rican soils (II) Senile latosol (Colorado Series). (B) Structure stability. Inter-American Institute of Agricultural Sciences. Turrialba, Costa Rica. 8 p.

HARRIS S.A. 1971a. Podsol development on volcanic ash deposits in the Talamanca range, Costa Rica, pp. 191-209. In: D.H Yaalon (ed). Paleopedology: origin, nature and dating of paleosols. Halsted Press. New York, USA

HARRIS S.A. 1971b. Quaternary vulcanicity in the Talamanca range of Costa Rica. Canadian Geographer 15(2):141-145. 
HERRE A., LANG F., SIEBE Ch., DOHRMANN R., KAUPENJOHANN M. 2007. Mechanisms of acid buffering and formation of secondary minerals in vitric Andosols. European Journal Soil Science 58:431-444.

HERRERA I.R. 1990. Geoquímica ambiental y geopedología de los suelos de una parte del Valle Central Occidental, Provincia de Alajuela, Costa Rica. Tesis de Licenciatura, Universidad de Costa Rica. San José, Costa Rica. 301 p.

HOLDRIDGE L.R., GRENKE W.C., HATHEWAY W.H., LIANG T., TOSI J.A. 1971. Forest environments in tropical life zones: a pilot study. Pergamon Press. Great Britain. 741 p.

JONGMANS A.G., DENAIX L., van OORT E., NIEUWENHUYSE A. 2000. Induration of C horizons by allophane and imogolite in Costa Rican volcanic soils. Soil Science Society America Journal 64:254-262.

JONGMANS A.G., MULDER J., GROENESTEIJN K., BUURMAN P. 1996. Soil surface coatings at Costa Rica recently active volcanoes. Soil Science Society America Journal 60:1871-1880.

JONGMANS A.G., van OORT E., JAUNET A., van DOESBURG J.D. 1994. Inheritance of 2:1 phyllosilicates in Costa Rican Andisols. Soil Science Society of America Journal 58:494-501.

KAUTZ C.Q., RYAN P.C. 2003. The $10 \AA$ to $7 \AA$ halloysite transition in a tropical soil sequence, Costa Rica. Clays and Clay Minerals 51:252-263.

KELLY E., CHADWICK O., HILINSKI T. 1998. The effect of plants on mineral weathering. Biogeochemistry 13:319-335.

KESEL R.H., SPICER B.E. 1985. Geomorphologic relationships and ages of soils on alluvial fans in the Rio General Valley. Costa Rica. Catena 12:149-166.

KLEBER M., SCHWENDENMANN L., VELDKAM E., RÖFFNER J., JAHN R. 2007. Halloysite versus gibbsite: silicon cycling as a pedogenetic process in two lowland neotropical rain forest soils of La Selva, Costa Rica. Geoderma 138:1-11.

KNOBLICH K., MANDS E., KUSSMAUL S. 1996. Estudios mineralógicos y físico-mecánicos en rocas volcánicas meteorizadas del Valle Central de Costa Rica. Revista Geología América Central 19/20:175181.

KREZDORN A.H., ROBERTSON W.K., REUSS L.A. 1967. Potential for citrus production in Costa Rica' Atlantic Zone. University of Florida/AID Mimeo Report. 31 p.

KUNZE G.W., BRADLEY W.F. 1976. Occurrence of a tabular halloysite in a Texas soil. In: Twelfth National Conference on Clays and Clay Minerals. 7 p.

LAGUNA J.E. 1983. Hydrothermal alteration and weathering of volcanic rocks of the Aguacate Formation
(Miocene-Pliocene) Costa Rica, Central America. Zbl. Geol. Paleont. Teil 1(3/4):223-233.

LAGUNA J.E. 1985. Mineralogía de las arcillas de las rocas volcánicas alteradas de la parte sur-central de la Cordillera de Tilarán, Costa Rica. Ciencia y Tecnología (CR) 9(1-2):11-27.

LANDAETA A., LÓPEZ C.A., ALVARADO A. 1978. Caracterización de la fracción mineral de suelos derivados de cenizas volcánicas de la Cordillera de Talamanca, Costa Rica. Agronomía Costarricense 2(2):117-129.

LANDAETA A. 1977. Caracterización de la fracción mineral y determinación del ZPC de una catena de suelos derivados de cenizas volcánicas de la Cordillera de Talamanca. Tesis de Licenciatura, Universidad de Costa Rica, San José, Costa Rica. 90 p.

LEWIS J.F., DRAPER G., PROENZA J.A., ESPAILLAT J., JIMÉNEZ J. 2006. Ophiolite-related ultramafic rocks (serpentinites) in the Caribbean Region: a review of their occurrence, composition, origin, emplacement and Ni-laterite soil formation. Geologica Acta 4(1-2):237-263.

LINDSAY W.L. 1979. Chemical equilibria in soils. John Wiley. New York. 449 p.

LÓPEZ C.A. 1963. Identificación y clasificación de los minerales de arcilla presentes en nueve suelos de Costa Rica. Tesis de Ingeniero Agrónomo, Universidad de Costa Rica, San José, Costa Rica. $56 \mathrm{p}$.

LÓPEZ H. 1978. Caracterización de la fracción mineral en cinco andepts de los cantones de Corredores y Coto Brus. Tesis de Ingeniero Agrónomo, Universidad de Costa Rica, San José, Costa Rica. 51 p.

LUIJCKX F., ZUNNENBERG W. 1992. Geomorphology and soils of the areas Limón-Cahuita, Atlantic Zone of Costa Rica. Report. Centro Agronómico Tropical de Investigación y Enseñanza/Atlantic Zone Programme (Costa Rica). No. 5. 55 p. Turrialba. CATIE. CR.

MALAGÓN C.D. 1975. Mineralogía de suelos: sus relaciones con génesis, fertilidad y clasificación de suelos. Instituto Geográfico Agustín Codazzi, Subdirección Agrológica, Volumen 11. $\mathrm{N}^{\circ} .1,828 \mathrm{p}$.

MALDONADO F.A. 1973. Study of a climo-sequence on soils developed on volcanic ash deposits in Ecuador. Ph.D. thesis. State University of Ghent, Belgium. $262 \mathrm{p}$.

MARTINIJ.A. 1969. Distribución geográfica y características de los suelos derivados de cenizas volcánicas de Centroamérica. In: Panel sobre suelos derivados de cenizas volcánicas de América Latina, Turrialba, FAO/IICA. A.5-A.19.

MATA R. 1982. Variaciones pedogenéticas en tres secuencias topográficas del Pacífico seco de Costa Rica. Tesis M.Sc. CATIE. Turrialba, Costa Rica. 147 p. 
MATA R., MELÉNDEZ G., REINSCH T. 2009. Suelos en una secuencia topográfica en la ladera suroeste del volcán Irazú: guía de campo. XVIII Congreso Latinoamericano de la Ciencia del Suelo. San José, Costa Rica 16 al 29 noviembre 2009. 40 p.

MATA R., VÁSQUEZ A., ROSALES A., SALAZAR D. 2012. Proyecto mapa digital de suelos de Costa Rica. ACCS- CIA-INTA. VII Congreso Nacional de Suelos. 6-8 nov. 2012. Hotel Barceló San José Palacio. San José, Costa Rica.

MATHERS S.J., MADRIGAL J.E., ALVARADO F. 1991. Results of an initial exploration programme for bentonitic clays in Costa Rica. Proyecto AngloCostarricense de Minerales Industriales (PACONI). BGS Technical Report WC / 90/36. 24 p.

MEIJER E.L., BUURMAN P. 2003. Chemical trends in a perhumid soil catena on the Turrialba volcano (Costa Rica). Geoderma 117:185-201.

MIZOTA C., van REEUWIJK L.P. 1989. Clay mineralogy and chemistry of soils formed in volcanic material in diverse climatic regions. Int. Soil Reference and Information Centre, Wageningen, the Netherlands. Soil Monograph 2. $185 \mathrm{p}$.

MOTAVAlli P., PALM C., ELliOT E., FREY S., SMITHSON P. 1995. Nitrogen mineralization in humid tropical forest soils: mineralogy, texture, and measured nitrogen fractions. Soil Science Society America Journal 59:1168-1175.

MURATA K.J., DONDOLI C., SAENZ R. 1966. The $1963-$ 65 eruption of Irazu volcano, Costa Rica. Bull. Volcanologique 29:766-796.

NDAYIRAGIJE S., DELVAUX B. 2003. Coexistence of allophane, gibbsite, kaolinite and hydroxy-Alinterlayered 2:1 clay minerals in a perudic Andosol. Geoderma 117:203-214.

NIEUWENHUYSE A. 1996. Soils, geology, and soil-related sustainability aspects of the perhumid tropical Limón basin, Costa Rica. Serie Técnica. Informe

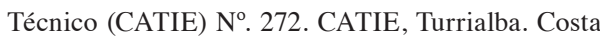
Rica. 85 p.

NIEUWENHUYSE A., van BREEMEN N. 1997. Quantitative aspects of weathering and neoformation in selected Costa Rican volcanic soils. Soil Science Society of America Journal 61(5):1450-1458.

NIEUWENHUYSE A., JONGMANS A.G., van BREMEN N. 1993. Andisol formation in a Holocene beach ridge plain under humid tropical climate of the Atlantic coast of Costa Rica. Geoderma 57:423-442.

NIEUWENHUYSE A., JONGMANS A.G., van BREMEN N. 1994. Mineralogy of a Holocene chronosequence on andesitic beach sediments in Costa Rica. Soil Science Society of America Journal 58:485-494.

NIEUWENHUYSE A., KROONENBERG S.B. 1994. Volcanic origin of Holocene beach ridges along the Caribbean coast of Costa Rica. Marine Geology 120:13-26.
NIEUWENHUYSE A., VERBIRG P.S.J., JONGMANS A.G. 2000. Mineralogy of a chronosequence on andesitic lava in humid Costa Rica. Geoderma 98:61-82.

OTAROLA C., ALVARADO A. 1977. Caracterización y clasificación de algunos suelos del Cerro de la Muerte, Talamanca, Costa Rica. Suelos Ecuatoriales 8(1):397-400.

PARFITT R.L., HENMI T. 1980. Structure of some allophanes from New Zealand. Clays Clay Minerals 28(4):285-294.

PELT E., CHABEAUX F., INNOCENT C., NAVARRE A.K., SAK P.B., BRANTLEY S.L. 2008. Uraniumthorium chronometry of weathering rinds: rock alteration rate and paleo-isotopic record of weathering fluids. Earth and Planetary Science Letters 276:98-105.

PHILliPS C.M., FOWLE D.A., TAUNTON A., HERNANDEZ W., MORA M., MOORE D., SHINOGLE H., ROBERTS J.A. 2014. Silicate dissolution in Las Pailas thermal field: Implications for microbial weathering in acidic volcanic hydrothermal spring systems. Geomicrobiology Journal 31(1):23-41.

PRINGLE C.M., PAABY P., VAUX P.D., GOLDMAN C.R. 1986. In situ nutrient assays of periphyton growth in a lowland Costa Rican stream. Hydrobiology 134:207-213.

PRINGLE C.M., ROWE G.L., TRISKA F.J., FERNÁNDEZ J.L., WEST J. 1993. Landscape linkages between geothermal activity, solute composition, and ecological response in streams draining Costa Ricas's Atlantic slope. Limnology and Oceanography 38:753-774.

PRINGLE C.M., TRISKA F.J., BROWDER G. 1990. Spatial variation in basic chemistry of streams draining a volcanic landscape on Costa Ricas's Caribbean slope. Hydrobiology 206:73-85.

QUANTIN P., BALESDENT J., BOULEAU A., DELAUNE M., FELLER C. 1991. Premier stades d'alteration de ponces volcaniques en climat tropical humide. (Montagne Pelee, Martinique). Geoderma 50:125148.

RAMÍREZ L., ALVARADO A., PUJOL R., McHUGH A., BRENES L.G. 2008. Indicadores para estimar la sostenibilidad agrícola de la cuenca media del río Reventado, Cartago, Costa Rica. Agronomía Costarricense 32(2):93-118.

REAGAN M.K., DUARTE E., SOTO G.J., FERNÁNDEZ E. 2006. The eruptive history of Turrialba volcano, Costa Rica, and potential hazards from future eruptions. Geological Society of America. Special Paper $\mathrm{N}^{\circ}$. 412. pp. 236-253.

REEVES R.D., BAKER A.J.M., ROMERO R. 2007. The ultramafic flora of the Santa Elena peninsula, Costa Rica: a biogeochemical reconnaissance. Journal of Geochemical Exploration 93:153-159. 
ROCHELle C.A., MilOdOWSKI A.E., SAVAGE D., CORELLA M. 1989. Secondary mineral growth in fractures in the Miravalles geothermal system, Costa Rica. Geothermics 18(1/2):279-286.

RYAN P.C., HUERTAS F.J. 2009. The temporal evolution of pedogenic $\mathrm{Fe}$-smectites to Fe-kaolin via interstratified kaolin-smectite in a moist tropical soil chronosequence. Geoderma 151(1/2):1-15.

SÁENZ A. 1949. Anotaciones sobre el origen de formación y desarrollo de los suelos de la región de Palmares y sus alrededores. Revista de la Universidad de Costa Rica 4:287-296.

SÁENZ A. 1951. El suelo en relación con los levantamientos agrológicos y de conservación. Facultad de Agronomía, Universidad de Costa Rica. San José, Costa Rica 96 p.

SÁENZ A. 1969. El perfil andosólico de Costa Rica. Departamento de Publicaciones, Universidad de Costa Rica. Serie de Textos No. 196. San José, Costa Rica. 10 p.

SÁENZ A. 1983. Lateritas y suelos lateríticos de Costa Rica. Facultad de Agronomía, Escuela de Fitotecnia, Universidad de Costa Rica. San José, Costa Rica. $19 \mathrm{p}$.

SÁENZ A., ALVARADO A. 1980. El perfil andosólico y el solum biodinámico. Facultad de Agronomía, Escuela de Fitotecnia, Universidad de Costa Rica. San José, Costa Rica. 7 p.

SAK P.B., FISHER G.M., GARDNER T.W., MURPHY K., BRANTLEY S.L. 2004. Rates of weathering ring formation on Costa Rica basalt. Geochimica and Cosmochimica Acta 68(7):1453-1472.

SALAZAR C. 2012. Caracterización mineralógica de arcillas de algunos suelos en la cuenca del río Savegre, Costa Rica. Proyecto de tesis. Maestría en Ciencias Agrícolas y Recursos Naturales con Énfasis en Suelos. Sistema de Estudios de Posgrado, Universidad de Costa Rica. San José, Costa Rica. $29 \mathrm{p}$.

SÁNCHEZ E.S. 1994. Análisis difractométrico. Laboratorio Petrología, Área de Geología, Dpto. Recurso Geotérmico, Instituto Costarricense de Electricidad. San José, Costa Rica. 2 p.

SANDOVAL D. 2010. Estudio detallado de suelos y determinación de la unidad de manejo en Finca Cedrela, La Gamba, Pacifico Sur de Costa Rica. Curso Manejo Integrado de Sistemas de Producción Agrícola II. Informe de Pasantía. Escuela de Agronomía, Universidad de Costa Rica. San José, Costa Rica. 17 p.

SCHELLMANN W. 1981. Considerations on the definition and classification of laterites, pp. 1-10. In: Proceedings of the International Seminar on Laterization Processes. Held at Trivandrum, India 11-14 diciembre, 1979. A.A. BALKEMA/ ROTTERDAM. New Delhi, India.
SCHEMBRE C.H. 2009. Soil types and fundamental soil properties of a Costa Rican tropical montane cloud forest, Reserve Cloudbridge, San Gerardo de Rivas, Cordillera de Talamanca. San José, Costa Rica. 37 p.

SCHEUCHER L.E.A., VORTISCH W., LAGUNA J. 2008. Geological and mineralogical investigations of the lithologies and their weathering products in a study area south-west of the field station "La Gamba", Golfo Dulce, Costa Rica, pp. 31-45. In: A. Weissenhofer, W. Huber, V. Mayer, S. Pamperi, A. Weber and G. Aubrecht (eds.). Natural history of the Golfo Dulce region, Costa Rica. Stapfia 88.

SHERROD D.R., VALLANCE J.W., TAPIA A., McGEEHIN J.P. 2008. Volcán Barú, eruptive history and volcano-hazards assessment. Reston, Virginia. U.S. Geological Survey Open-File Report 2007-1401. $33 \mathrm{p}$.

SHOJI S., NANZYO M., DAHLGREN R.A. 1993. Volcanic ash soils: genesis, properties and utilization. Elsevier. Developments in Soil Science 21. 288 p.

SHOJI S. 1986. Mineralogical characteristics, 1. Primary minerals. pp 21-40. In: K. Wada (ed.), Ando Soils in Japan. Kyushu University Press, Fukuoka, Japan.

SIEFFERMANN G., MILLOT G. 1969. Equatorial and tropical weathering of recent basalts from Cameroon: allophanes, halloysite, metahalloysite, kaolinite and gibbsite, pp. 417-430. In: Proc. Int. Clay Conf., Tokio, Japan. Vol 1.

SOIL SURVEY STAFF. 1999. Soil taxonomy, a basic system of soil classification for making and interpreting soil surveys. 2nd. ed. USDA-NRCS. Agriculture Handbook $N^{\circ} .436 .869$ p.

SOIL SURVEY STAFF. 2006. Keys to soil taxonomy. 9th. Ed., Washington, USA. Natural Resources Department of Agriculture. United States, Department of Agriculture. 321 p.

SOTO G.J., ALVARADO G.E., GOOLD S. 2003. Erupciones $<3800$ a.P. del volcán Rincón de La Vieja, Costa Rica. Revista de Geología de América Central 29:67-86.

SOTO J.A. 1998. Formas de fósforo y su liberación en Andisoles de la región central oriental de Costa Rica. Tesis de doctorado, Universidad de Córdoba, España. $155 \mathrm{p}$.

SOTO M., GONZÁLEZ R. 1956. Estudio geoquímico y geoagronómico de los suelos de Costa Rica. Tesis de Ingeniero Agrónomo, Universidad de Costa Rica. San José, Costa Rica. 126 p.

SPOSITO G. 1989. The chemistry of soils. Oxford University Press, New York, NY.

STAFF OF THE CACAO PROGRAM. 1963. La Lola cacao farm. Cacao. Inter-American Institute of Agricultural Sciences. Turrialba 8(2):1-40.

STOORVOGEL J.J., EPPINK G.P. 1995. Atlas de la Zona Atlántica Norte de Costa Rica. Guápiles, Costa Rica. Programa Zona Atlántica (CATIE/UAV/MAG). 
STOTZKY G., MARTIN R.T. 1963. Soil mineralogy in relation to spread of Fusarium wilt of banana in Central America. Plant and Soil 16(3):317-337.

TAN K., PERKINS H., CREERY M.C. 1975. Amorphous and crystalline clays in volcanic ash soils of Indonesia and Costa Rica. Soil Science 119(6):431-440.

THOMAS M.F. 1994. Geomorphology in the tropics: a study of weathering and denudation in low latitudes. JOHN WILEY \& SONS. Chichester Ingland. $460 \mathrm{p}$.

USDA-SCS. 2012. Soil survey laboratory primary characterization, data of some Costa Rican soils. Internal Report. Lincoln, Nebraska. sp.

VALENTON I. 1972. Bauxites. Developments in Soil Science 1. Elsevier Publishing Company. Amsterdam, Holland. $226 \mathrm{p}$.

VAN DOOREMOLEN W.A., WIELEMAKER W.G., van REEMEN N., MEIJER E.M., van REEWIJK L.P. 1990. Chemistry and mineralogy of Andosols of various age in a soil chronosecuence of andesitic lahars in Costa Rica. 2nd. International Symposium, Geochemistry of the earth's surface and of mineral formation. Aix en Provence, France. Chemical Geology, Journal of the European Association for Geochemistry 84(1/4):39-141.

VEGA E. 2004. Identificación de minerales de muestras recolectadas en el proyecto Las Pailas. ICE. Laboratorio de Geología. GEO-038-2004. San José. Costa Rica. sp.

VEGA E., CHAVARRÍA L., BARRANTES M., MOLINA F., HAKANSON E.C., MORA O. 2005. Geologic Model of The Miravalles Geothermal Field, Costa Rica, pp. 1-5. In: Proceedings World Geothermal Congress 2005, Antalya, Turkey.

WADA K. 1989. Allophane and imogolite, pp. 1051-1087. In: J.B. Dixon and S.B. Weed (eds.). Minerals in Soil Environment. $2^{\text {nd }}$ ed. SSSA Book Series, 1. Madison, WI.
WERNER P. 1984. Changes in soil properties during tropical wet forest succession in Costa Rica. Biotropica 16(1):43-50.

WIDMER Y. 1999. Soil characteristics and Chusquea bamboos in the Quercus forests of the Cordillera de Talamanca, Costa Rica, pp. 63-83. In: Y. Widmer. The ecological role of bamboo (Chusquea spp.) in the old-growth Quercus forests of the Cordillera de Talamanca, Costa Rica. ETH Nr. 13186. Zürich University. Chapter 3.

WILKE W., KRETZSCHMAR S., BUNDT M., SOBORÍO G., ZECH W. 2000. Depth distribution of aluminum and heavy metals in soils of Costa Rica coffee cultivation areas. Journal of Plant Nutrition and Soil Science 163:499-502.

WINOWIECKI L. 2008. Soil biochemical patterns in the Talamanca foothills, Costa Rica: local soil knowledge and implications for agroecosystems. Ph. D. Dissertation, Ohio University/Centro Agronómico Tropical de Investigación y Enseñanza. USA. 172 p.

WINTERS A.F. 1997. Soils on the Pleistocene Ignimbrite Bagaces Formation, Guanacaste, Costa Rica: a report on the results of two thesis. Department of Soil Science and Geology. Agricultural University of Wageningen, The Netherlands. 68 p. (Apéndices).

ZAPATA R. 2006. Química de los procesos pedogenéticos. Escuela de Geociencias, Facultad de Ciencias, Universidad Nacional de Colombia, Sede Medellín. Colombia. $358 \mathrm{p}$.

ZEASER D., JADAN S., POSSO G. de. 1988. Zonificación de especies forestales en la región interandina del Ecuador. Dirección Nacional Forestal, Ministerio de Agricultura/Agencia Desarrollo Internacional. Quito, Ecuador. 105 p.

ZEHETNER F., MILLER W.P., WEST L.T. 2003.Pedogenesis of volcanic ash soils in Andean Ecuador. Soil Science Society of America Journal 67:1797-1809. 